\title{
Accidental burning of a fuel layer on a waterbed: a scale analysis of the models predicting the pre-boilover time and tests to published data
}

\author{
J. Hristov $^{\text {a,* }}$, E. Planas-Cuchi ${ }^{\text {b }}$, J. Arnaldos ${ }^{\text {b }}$, J. Casal $^{\text {b }}$ \\ a Department of Chemical Engineering, University of Chemical Technology and Metallurgy, Kliment Ohridsky 8, 1756 Sofia, Bulgaria \\ ${ }^{\mathrm{b}}$ Department of Chemical Engineering, Center for Studies of Technological Risk (CERTEC), Universitat Politecnica de Catalunya, Diagonal 647, \\ 08028 Barcelona, Spain
}

Received 12 December 2002; accepted 16 June 2003

\begin{abstract}
The paper concerns the heat transfer models of liquid fuel bed burning on water sublayer. The main efforts are stressed on the qualitative assessment of models available and their adequacy as well as on the prediction of the boilover onset. The analysis employed various data obtained by different research groups. The evaluation of the suitable functional relationships predicting the pre-boilover time was done based on dimensionless groups derived from two types of models published in the literature: Surface Absorption Models and In-Depth Absorption Models.
\end{abstract}

(c) 2003 Elsevier SAS. All rights reserved.

\section{Introduction}

Boilover is generally considered as one of the most dangerous fire phenomena in large-scale oil-tank fires. Usually, there is a water sublayer consisting of water collected in the lower parts of the tanks due to different reasons- condensation effects or fire-fighter actions, for example. When a fuel is burning the heat release from the flame heats the unburned fuel to its boiling point. The heat from the burning surface is transferred through the unburned fuel toward the underlying waterbed. When water sublayer accumulates a certain quantity of heat energy it starts to vaporize. The burning fuel expel occurs in three main forms [1]: (i) Slop over occurs as a discontinuous frothing release of fuel from the tank on one side of its wall. (ii) Froth over is a continuous low intensity fuel release (frothing) from the tank over its walls similar to the "rolling effect" occurring during the tank filling [1]. (iii) Boilover is a violent ejection of the fuel that results in an enormous fire enlargement and formation of fireballs and a frothing over the entire tank content. The burning

\footnotetext{
* Corresponding author.

E-mail addresses: jyh@uctm.edu, jordan.hristov@mail.bg (J. Hristov), joaquim.casal@upc.es (J. Casal).
}

fuel spillage implies an enormous danger for surroundingsequipment and humans.

The boilover phenomenon is interesting from a fundamental point of view, especially its mechanism and the theoretical prediction of the critical condition of its onset. Blinov and Khudyakov in their early book [2] have reported a hot zone formation in the fuel layer (crude oil and kerosene) during the burning process considering a distillation process of the fuel components. The boilover phenomenon is quite complicated and at present is under intensive research [3-7]. Originally, the term was referred to tank fires, but recently it was applied as thin-layer boilover to the burning of thin slicks of oils in order to limit the spill spread after an accidental release $[6,8-10]$.

\section{Scope of the problem}

The major efforts of the investigators have been stressed on the parameters of the fire subsystem: the size of fuel layer/water sublayer [5-7] as conditions predefining the boiler appearance and its intensity. Several major factors have been concerned: (i) Burning rate; (ii) Time to start the boilover; (iii) Boilover intensity; (iv) Liquid temperature history effect on the fuel boiling point; (v) Developing of the "hot zone" through the fuel layer. Moreover, the geometries 


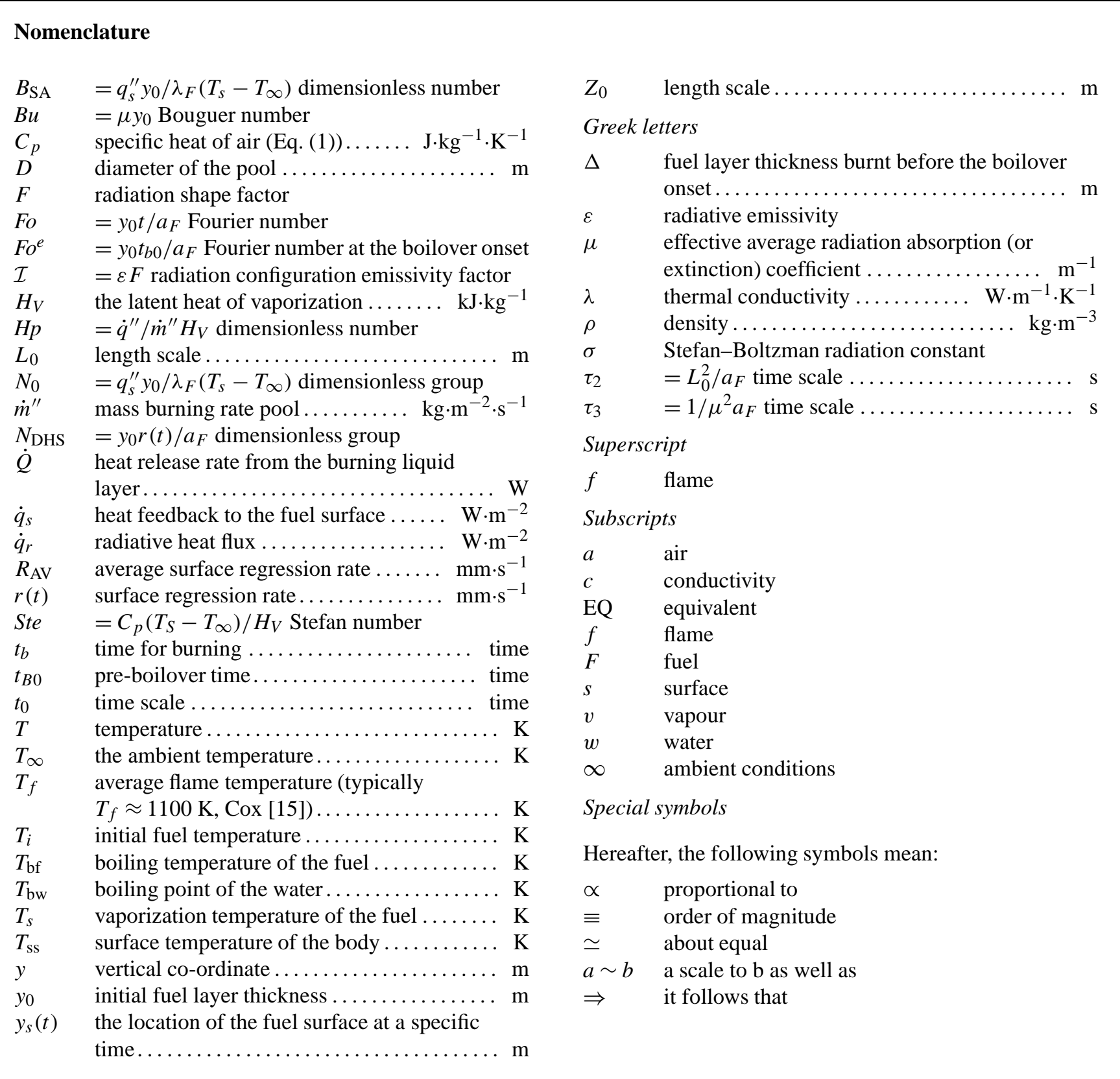

of both the pool and the fuel layer have a great impact on the burning rate and the pre-boilover time $[9,10]$. The problems have been investigated mainly via experiments and simple heat conduction models have been developed. The further analysis employs two major group of results published:

(i) Experimental data concerning the pre-boilover time;

(ii) Models developed for the temperature distribution across the fuel layer.

\subsection{Models developed-a brief summary and a classification}

Twardus and Brzustowski [11] did the first attempt by a development of simple one-dimensional model with heat losses towards the water sublayer. Later the model was developed to incorporate the radiative absorption in the fuel [12]. Alramadhan et al. [13] have developed a more realistic model incorporating the radiative feedback of the flame and the turbulent buoyant motion. Garo at al. [6] reported recently one-dimensional both single and double layer models. The efforts have been focused on the fuel layer/waterbed parameters [3-7] predefining the "boilover" appearance and its intensity. Both the physical situation and the common used model scheme are sketched on Fig. 1. The models developed are summarized in Table 1 . All of them are onedimensional models and could be classified into two major groups: 
Table 1

1-D Single-layer models developed and solutions available

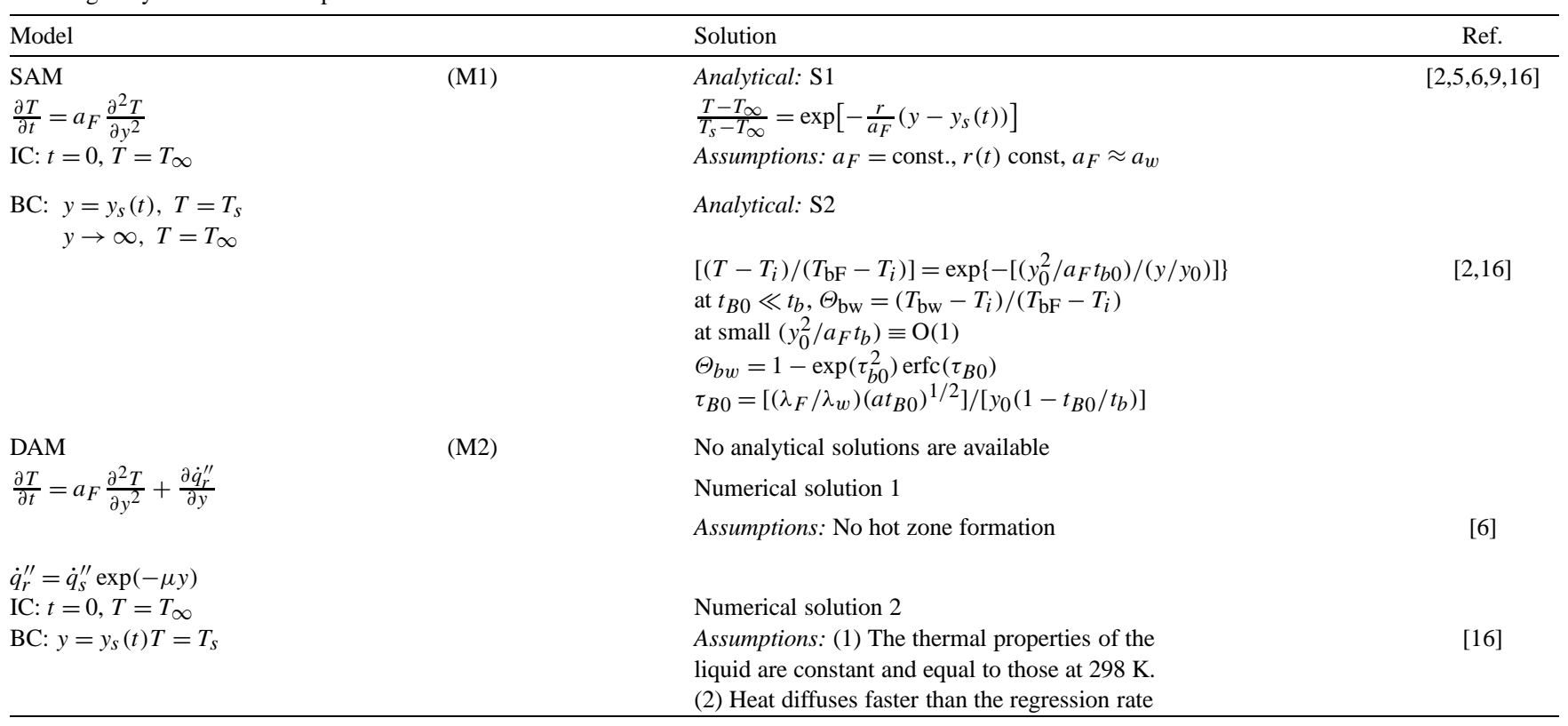

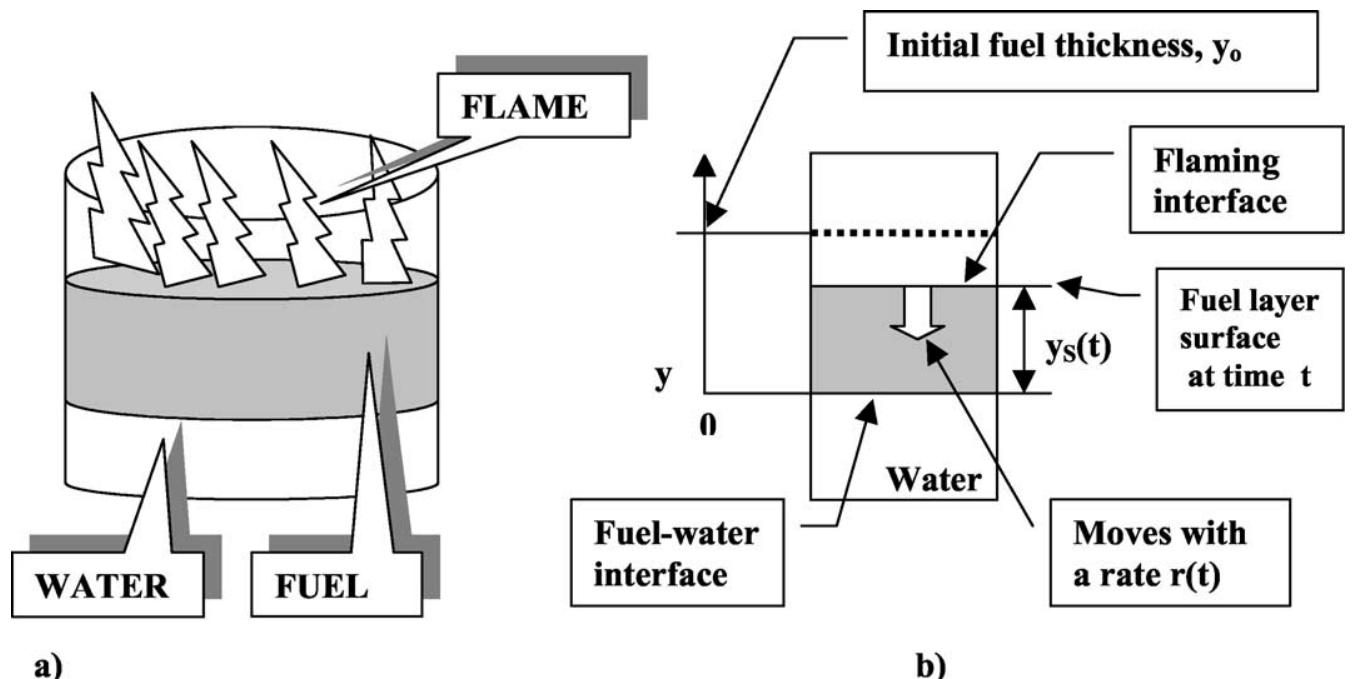

Fig. 1. Burning fuel layer on waterbed—schematically: (a) Physical situation; (b) A scheme employed by the 1-D models discussed.

- Surface Absorption Models (SAM) without a volumetric source term.

- In-Depth Absorption Models (DAM) concerning a volumetric heat source depending on the vertical coordinate and relevant to the radiation flux to the fuel surface.

Both groups of models do not concern the formation of a hot zone. Broekmann and Schecker [1] proposed the only model that concerns it. It was excluded from the present analysis for the clarity of explanation and more uniform data arrangement. A separate study will concern it further. Moreover, these models and the further analysis do not consider the effects of the "lips" (tank walls above the burning surface) bounding the flame.

\subsection{Physical conditions at the boundaries of the burning layer}

The heat release rate from a pool fire can be expressed as $[12,14,15]$ :

$\dot{Q}=\rho_{\infty} C_{p}\left[T_{\infty}^{f} g\left(T_{f}-T_{\infty}^{f}\right)\right]^{1 / 2} D^{5 / 2}$

Therefore, the net heat feedback from the flame (per unit area) reaching the surface of the burning liquid is a fraction 
of the total heat released $\chi$ (independent of the pool diameter) $[16,17]$ :

$\dot{q}_{s}^{\prime \prime}=\left(\frac{4 \chi}{\pi}\right) \rho_{\infty} C_{p} \sqrt{T_{\infty}^{f} g\left(T_{f}-T_{\infty}^{f}\right)} \sqrt{D}$

The basic assumptions of the models are:

(i) A heat conduction mechanism is assumed, i.e., no convection inside the fuel layer occurs.

(ii) The radiation is fully absorbed at the surface $y=y_{s}(t)$, where the energy balance is:

$\dot{q}_{s}^{\prime \prime}=H_{V} \rho_{F} r(t)+\dot{q}_{c}^{\prime \prime}$

while the boundary condition at the burning surface (fuel side) is defined by

$$
\dot{q}_{c}^{\prime \prime}=-\left.\lambda_{F} \frac{\partial T}{\partial y}\right|_{y=y_{s}(t)}
$$

The surface regression rate $[16,17])$ is:

$r(t)=\frac{\partial y_{s}(t)}{\partial t}=\frac{\dot{m}^{\prime \prime}}{\rho_{F}}$

The contact line between the fuel and the water sublayer assumes

$\dot{q}_{c}^{\prime \prime}=-\left.\lambda_{F} \frac{\partial T}{\partial y}\right|_{\text {fuel }}=-\left.\lambda_{w} \frac{\partial T}{\partial y}\right|_{\text {water }}$

Despite these formulations, all the models consider Dirichlet boundary condition $\left(T=T_{s}\right.$ at $\left.y=y(t)\right)$ due the phase transition (the fuel vaporization) at the burning interface. The energy balances at the interface (3) and the condition (4) have not been considered. The only attempt to employ (3) was performed by Garo et al. [6,9], but for predicting the surface regression rate, not as a problem boundary condition.

\subsection{Study aim, problems and tactics of the scale analysis}

The models discussed here consider only the top layer conditions, i.e. single layer models will be discussed. This simplification allows to recover more information at this initial step of systematization of the information and permits to provide more clear information from the dimensional analysis applied. Generally, the solutions look for the time, $t_{B 0}$, corresponding to the case $T_{y=0}=$ boiling temperature of the water as a boilover onset criterion. The solutions (analytical or numerical) have been performed in a dimensional form strongly related to the size of the experimental set-up used. It seems strange, but there are no solutions (or analysis) of the models (see Ref. [6,9] for example) performed in dimensionless forms. Recently, an attempt for systematization of data dispersed in various sources was done [18] and a simple dimensional analysis of the models was performed. The analysis developed here follows several steps:

(1) A study of the existing models via dimensionless variables well known from the transient heat transfer problems of semi-infinite solids and the adequacy of the boundary conditions employed. Evaluation of new dimensionless groups being specific for the heat transfer process.

(2) Evaluation of the true scales (time and length) via model analysis and assumptions of a dominating heat transfer mechanism.

(3) Similitude tests of published data.

These steps form the skeleton of the analysis and tend to present the physics of the problem, but not only mathematical manipulations of the models.

\section{Dimensionless groups development}

\subsection{Assumptions and dimensionless variables}

The scale analysis assumes some simplifications of the problem: (1) The model considers the fuel layer only and no effects of the heat transfer with the water sublayer are accounted; (2) The fuel layer is assumed with a constant thickness. These assumptions try to focus the efforts on models accompanied by adequate and reliable experimental data. The latter needs some explanations. The surface regression rate, $r(t)$, is a complex function of the fuel properties and the vessel geometry $[5-7,17]$.

Generally, the models created are moving-boundary problems. The further analysis considers them as fixed boundaries problems in order to evaluate the main dimensionless groups controlling the process. This approximation tends to establish gradually:

(1) the complex nature of the heat transfer due to burning surface of the fuels, and;

(2) to identify the dimensionless group predicted by the scaling of the terms of the equations.

As a first step, the following scales and dimensionless variables were selected:

Length: The initial fuel layer depth $y_{0}$, so $y^{*}=y / y_{0}$; Temperature: $\Theta=\left(T-T_{\infty}\right) /\left(T_{s}-T_{\infty}\right)$; Time: a specific time $t_{0}, t^{*}=t / t_{0}$ (the specification of $t_{0}$ will be done further through the analysis).

The scales are defined in a manner that is classical for the unsteady heat conduction problems and available in every textbook on heat transfer (in this case $t_{0}=y_{0}^{2} / a_{F}$, for example).

The non-dimensionalization of the equations yields:

- Surface absorption models (SAM) (see M1 in Table 1)

$\frac{\partial \Theta}{\partial t^{*}}=\left(\frac{a_{F} t_{0}}{y_{0}^{2}}\right) \frac{\partial^{2} \Theta}{\partial y^{* 2}}$

The only possible dimensionless group is the Fourier number $F o=a_{F} t_{0} / y_{0}^{2}$. The condition $T=T_{s}$ (at the moving surface) does not generate a specific dimensionless group, but it participates the reference temperature $T_{s}-T_{\infty}$. 
- In-depth absorption models (DAM) (see M2 in Table 1)

$$
\begin{aligned}
\frac{\partial \Theta}{\partial t^{*}}= & \left(\frac{a_{F} t_{0}}{y_{0}^{2}}\right)\left(\frac{\partial^{2} \Theta}{\partial y^{* 2}}\right) \\
& +\frac{\mu \dot{q}_{s}^{\prime \prime} t_{0}}{\rho_{F} C_{p}\left(T_{s}-T_{\infty}\right)} \cdot \exp \left[-\left(\mu y_{0}\right) y^{*}\right]
\end{aligned}
$$

and contains two dimensionless groups only:

$F o=\frac{a_{F} t_{0}}{y_{0}^{2}} \quad$ and $\quad N_{\mathrm{VA}}=\frac{\left(\mu \dot{q}_{s}^{\prime \prime}\right) t_{0}}{\rho_{F} C_{p}\left(T_{s}-T_{\infty}\right)}$

as well as the dimensionless absorption attenuation product $\left(\mu y_{0}\right)=B u$-Bouguer number. In a more general form, $N_{\mathrm{VA}}$ is as a generation number $\left(Q_{g}\right)$ [19] (the subscript VA used here means Volumetric Absorption).

\section{Analysis of the dimensionless groups and their adequacy}

\subsection{SAM equations}

In fact, all the processes expressed through the models consider a period of time $t \leqslant t_{B 0}$. Thus, it is reasonable to introduce the pre-boilover time $t_{B 0}$ in the Fourier number as

$F^{e}=\frac{a_{F} t_{B 0}}{y_{0}^{2}}$

in order to evaluate the order of magnitude of that group at the boilover onset. The experimental results $[5,8]$ summarized (see Tables 2-4) indicate that $\mathrm{FO}^{e}$ is always lower than unity. Thus, the solution is that developed by Blinov and Khudyakov [2] and Arai et al. [21] (see Table 1)

$\Theta \equiv \operatorname{erfc}(y / 2 \sqrt{a t}) \equiv 1 / \sqrt{F_{O}}\left(y / y_{0}\right)$

Table 2

\begin{tabular}{|c|c|c|c|c|c|c|c|c|c|}
\hline Ref. & $\begin{array}{c}D \\
{[\mathrm{~m}]}\end{array}$ & $\begin{array}{c}y_{0}^{\mathrm{c}} \\
{[\mathrm{mm}]}\end{array}$ & $\begin{array}{l}t_{B 0}{ }^{\mathrm{a}} \\
{[\mathrm{sec}]}\end{array}$ & $\begin{array}{l}U_{T} \times 10^{3 \mathrm{a}} \\
{\left[\mathrm{mm} \cdot \mathrm{s}^{-1}\right]}\end{array}$ & $F_{O}^{e \mathrm{a}}$ & $\begin{array}{l}R_{\mathrm{AV}} \times 10^{2} \\
{\left[\mathrm{~mm} \cdot \mathrm{s}^{-1}\right]}\end{array}$ & $\left(\frac{\Delta}{y_{0}}\right)^{\mathrm{b}}$ & $N_{\text {DHS }}$ & $N_{\mathrm{VA}} \times 10^{3}$ \\
\hline \multirow{6}{*}{$\begin{array}{l}{[6,9]} \\
\text { Heating oil } \\
\left(a_{F}=0.877 \times 10^{-7} \mathrm{~m}^{2} \cdot \mathrm{s}^{-1}\right)^{\mathrm{c}}\end{array}$} & \multirow[t]{6}{*}{0.15} & 19 & 945 & 20.1 & 0.22 & \multirow[t]{7}{*}{$0.01^{\mathrm{b}}$} & 0.46 & 1.9 & 7.02 \\
\hline & & 17 & 830 & 20.48 & 0.24 & & 0.45 & 1.7 & 5.75 \\
\hline & & 13 & 625 & 20.8 & 0.31 & & 0.43 & 1.5 & 3.31 \\
\hline & & 9 & 450 & 20.0 & 0.47 & & 0.43 & 1.3 & 1.58 \\
\hline & & 7 & 340 & 20.58 & 0.59 & & 0.41 & 0.7 & 0.99 \\
\hline & & 4 & 165 & 24.42 & 0.88 & & 0.39 & 0.4 & 0.33 \\
\hline \multirow[t]{14}{*}{ Ste $=1.373$} & & 2 & 90 & 22.22 & 1.94 & & 0.18 & 0.2 & 0.007 \\
\hline & \multirow[t]{7}{*}{0.23} & 17 & 710 & 23.94 & 0.21 & \multirow[t]{7}{*}{$0.011^{\mathrm{b}}$} & 0.45 & 1.7 & 7.01 \\
\hline & & 15 & 620 & 24.19 & 0.23 & & 0.44 & 1.5 & 4.71 \\
\hline & & 13 & 530 & 24.52 & 0.27 & & 0.43 & 1.3 & 4.1 \\
\hline & & 9 & 340 & 26.47 & 0.36 & & 0.38 & 0.9 & 2.02 \\
\hline & & 4 & 125 & 32.0 & 0.66 & & 0.28 & 0.4 & 0.39 \\
\hline & & 3 & 75 & 40 & 0.71 & & 0.205 & 0.3 & 0.21 \\
\hline & & 2 & 30 & 66.66 & 0.64 & & 0.093 & 0.2 & 0.009 \\
\hline & \multirow[t]{6}{*}{0.5} & 15 & 345 & 43.47 & 0.13 & \multirow[t]{6}{*}{$0.017^{\mathrm{b}}$} & 0.37 & 1.5 & 6.95 \\
\hline & & 13 & 265 & 49.05 & 0.13 & & 0.32 & 1.3 & 6.04 \\
\hline & & 11 & 190 & 57.89 & 0.13 & & 0.27 & 1.1 & 4.33 \\
\hline & & 7 & 90 & 77.77 & 0.15 & & 0.18 & 0.7 & 2.89 \\
\hline & & 5 & 70 & 71.42 & 0.24 & & 0.2 & 0.5 & 0.85 \\
\hline & & 3 & 15 & 200 & 0.24 & & 0.05 & 0.3 & 0.329 \\
\hline [20] & 0.3 & 3.5 & 612 & 57.18 & 0.003 & no data & no data & & \\
\hline \multirow{2}{*}{$\begin{array}{l}\text { Arabian light crude oil } \\
\left(a_{F}=0.679 \times 10^{-7} \mathrm{~m}^{2} \cdot \mathrm{s}^{-1}\right)^{\mathrm{c}}\end{array}$} & \multirow[t]{2}{*}{0.6} & 20 & 492 & 40.65 & 0.083 & 2.33 & 0.574 & 6.87 & 6.87 \\
\hline & & 69 & 942 & 73.25 & 0.013 & 3.33 & 0.455 & 33.87 & 33.87 \\
\hline \multirow[t]{6}{*}{ Ste $=1.703$} & \multirow[t]{4}{*}{1} & 20 & 681 & 42.73 & 0.079 & 2.91 & 0.682 & 8.59 & 8.59 \\
\hline & & 40 & 978 & 40.89 & 0.041 & 3.66 & 0.896 & 21.6 & 21.6 \\
\hline & & 60 & 1310 & 45.87 & 0.024 & 4.0 & 0.872 & 35.34 & 35.34 \\
\hline & & 100 & 1926 & 51.92 & 0.013 & 3.66 & 0.706 & 54 & 54.0 \\
\hline & 2 & 20 & 411 & 48.66 & 0.069 & 3.08 & 0.633 & 9.08 & 9.08 \\
\hline & $(3.5)^{d}$ & 27 & 402 & 67.16 & 0.037 & 3.83 & 0.570 & 15.24 & 15.24 \\
\hline
\end{tabular}

Data summarized from various experiments and new results derived from them

a Calculated in [18];

b Present work data recovered from various papers of Garo et al.;

c From [6];

$\mathrm{d}$ The diameter of the circular pan with the same area, while the real square pan is $2.7 \times 2.7 \mathrm{~m}$ pan; $U_{\mathrm{T}}$ and $R_{\mathrm{AV}}$ data of Koseki experiments are from the original work [20], but recalculated here in $\left[\mathrm{mm} \cdot \mathrm{s}^{-1}\right]$. 
Table 3

Pre-boilover time of fuel burning for various fuels. Data summarized from the experiments of Garo et al. [6,9]. For all the experiments, $D=0.15 \mathrm{~m}$; $y_{0}=13 \mathrm{~mm}$. Present authors calculations

\begin{tabular}{lccc}
\hline Fuel & $\begin{array}{c}a_{F} \times 10^{7} \\
{\left[\mathrm{~m}^{2} \cdot \mathrm{s}^{-1}\right]}\end{array}$ & $\begin{array}{c}t_{B 0} \\
{[\mathrm{sec}]}\end{array}$ & $F^{e}=\frac{a t_{B 0}}{y_{0}^{2}}$ \\
\hline Crude oil & 0.679 & 669 & 0.269 \\
Heating oil & 0.877 & 670 & 0.348 \\
Hexadecane & 0.724 & 924 & 0.397 \\
$n$-Decane & 0.768 & 1095 & 0.498 \\
Xylene & 1.096 & 730 & 0.474 \\
$n$-Octane & 0.841 & 912 & 0.454 \\
Toluene & 0.951 & 582 & 0.327 \\
\hline
\end{tabular}

Table 4

Treatment of the data of Arai et al. [21] concerning the boilover onset. $D=0.048 \mathrm{~m} ; y_{0}=10 \mathrm{~mm}$

\begin{tabular}{|c|c|c|c|c|c|c|c|}
\hline Fuel & $\begin{array}{c}a_{F} \times 10^{7 \mathrm{a}} \\
{\left[\mathrm{m}^{2} \cdot \mathrm{s}\right]}\end{array}$ & $\begin{array}{c}T_{i} \\
{[\mathrm{~K}]}\end{array}$ & $\begin{array}{l}T_{b}{ }^{\mathrm{a}} \\
{[\mathrm{K}]}\end{array}$ & $\begin{array}{c}\langle r(t)\rangle \times 10^{5 \mathrm{a}} \\
{\left[\mathrm{m}^{2} \cdot \mathrm{s}\right]}\end{array}$ & $F_{O}^{e \mathrm{~b}}$ & Ste & $N_{\text {DHS }}$ \\
\hline Toluene & 1.03 & $\begin{array}{l}293 \\
318 \\
323 \\
325 \\
341 \\
355\end{array}$ & 383 & 1.35 & $\begin{array}{l}0.43 \\
0.29 \\
0.42 \\
0.45 \\
0.74 \\
1.01\end{array}$ & $\begin{array}{l}0.462 \\
0.332 \\
0.305 \\
0.295 \\
0.214 \\
0.143\end{array}$ & 1.35 \\
\hline Ethyl Benzene & 0.88 & $\begin{array}{l}293 \\
323 \\
330 \\
345\end{array}$ & 409 & 1.5 & $\begin{array}{l}0.45 \\
0.24 \\
0.18 \\
0.08\end{array}$ & $\begin{array}{l}0.558 \\
0.432 \\
0.398 \\
0.322\end{array}$ & 1.69 \\
\hline$n$-Decane & 0.753 & $\begin{array}{l}293 \\
323 \\
348 \\
355 \\
362\end{array}$ & 433 & 1.19 & $\begin{array}{l}0.34 \\
0.22 \\
0.11 \\
0.10 \\
0.07\end{array}$ & $\begin{array}{l}1.149 \\
0.892 \\
0.694 \\
0.636 \\
0.581\end{array}$ & \\
\hline
\end{tabular}

a The paper of Garo et al. [6] was used as a source for some average values of the fuel properties due to deficiencies in the original paper [21].

b From [18].

i.e., the well-known lumped capacitance solution [19] with a boundary condition $T_{\mathrm{bF}}=T\left[y_{s}(t)\right]$ at the moving fuel surface. The approach requires a knowledge of $r(t)$ in order to calculate $y_{s}(t)$ explicitly. Garo et al. [6,9] showed that it works well with an average value $R_{\mathrm{AV}}=\langle r(t)\rangle$ (See the corresponding column of Table 2) calculated through the initial parameters of the process (that practically simplifies the moving boundary problem). The substitution of $\left.T\right|_{\text {fuel/water }}-T_{\mathrm{wb}}$ in $\Theta$ transforms this dependent variable into a parameter. This allows to predict the pre-boilover time through the value of $F o \Longrightarrow t_{B 0}=\left(y_{0}^{2} / a_{F}\right) F^{e}$.

\subsubsection{Contributions of the initial fuel layer conditions to the pre-boilover time}

The SAM equations have a deficiency and do not provide information about some important initial parameters predetermining the pre-boilover time. This concerns the effects of: (1) The geometry (the size) of the fuel layer, and (2) The initial fuel layer temperature.
The experimental data indicate that the values of $\mathrm{Fo}^{e}$ increase as the fuel thickness decreases and the pan diameters are increased (see Table 2 for example, more data are collected in [18]). More precisely, $F_{O}{ }^{e}$ is strongly affected by the pool diameter through the ratio $y_{0} / D$. Physically, $F^{e}{ }^{e}=f\left(y_{0} / D\right)$ follows from the fact that for small-size pool fires the burning rate depends on the pool diameters. It was demonstrated that the correlation of the ratio $\left(\dot{m}^{\prime \prime} / B\right)=$ $f(D)$ (Fig. 12 of [22]) for burning hydrocarbons exhibits an asymptotic value at $D>2.5 \mathrm{~m}$, while for $D<1 \mathrm{~m}$ the slope of the line is very sharp (e.g., $r(t))$ depends on the pool diameters $[6,9,17-22])$. Here $B$ is known as Spalding's "diffusive transfer number" $[22,23]$ and it is independent of the mass vaporization rate (i.e. the surface regression rate) and depends mainly on the intrinsic properties of the fuels [22]. In other words, the fraction of the heat reflux the fuel surface [22]

$\chi=\frac{H_{V}}{H_{C}}=\frac{1}{B}$

is a value independent of the pool diameter (see the statement about $\chi$ concerning Eq. (2)). Some data are available in Table 4 (see further).

The data obtained by Arai et al. [21] indicate that the pre-boilover time depends on the initial fuel temperature (Table 4). This is the unique report concerning the initial fuel temperature effect. According to the results of Arai et al. [21], the higher initial temperature, shorter pre-boilover time. No-data correlations or model has been established previously. The fact implicitly indicates that the shorter preboilover times correspond to the water layers with higher initial temperatures. The heating of the fuel layer before the fire onset, in the experiments of Arai et al. [21], implies heating of the water sublayer due to the heat transfer through the interface. These comments do not exist in the original study of Arai et al. [21], but follows from the analysis of the experimental situation described.

\subsubsection{Simple scaling of the effects of initial fuel layer conditions [18]}

The model deficiency could be avoided through simple scaling of experimental data (recovered from [6-10,21]). The recent attempts [18] yield (data from Tables 2 and 3, for example):

$F^{e} f\left(y_{0} / D\right) \rightarrow F^{e} \sim\left(y_{0} / D\right)^{-0.5}$

The effect of the initial fuel temperature on $\mathrm{Fo}^{e}$ was scaled through the introduction of a dimensionless parameter $\Delta \Theta_{B}=\left(T_{\mathrm{bF}}-T_{i}\right) /\left(T_{\mathrm{bF}}-T_{\mathrm{bw}}\right)$, where $T_{i}$ is the initial fuel temperature. The $\Delta \Theta_{b}$ was introduced intuitively, ad hoc, in a form similar to dimensionless temperature, $\Theta$. The main reasons for that are: (i) The temperature at the burning surface practically equals the temperature of fuel saturation, i.e., the fuel boiling temperature; (ii) The water sublayer "explodes" when it reaches its boiling point; (iii) Therefore, higher initial temperature of the fuel, shorter pre-boilover 
period; (iv) On the other hand, smaller difference between the boiling points of the water and the fuel, shorter preboilover period in accordance with the assumptions of the models considered. This scaling will be used further for the regression analysis of the data.

The arrangement of the only available data of Arai et al. [21] yield [18] (see Table 4):

$\mathrm{Fo}^{e} \sim\left(\Delta \Theta_{b}\right)^{\approx 2} \Longrightarrow \frac{F^{e}}{\left(\Delta \Theta_{b}\right)^{2}} \sim C \frac{1}{\sqrt{y_{0}} / D}$

where the factor $C \sim D^{-3 / 2}$.

Thus, in an explicit form we have

$t_{B 0} \sim\left(\Delta \Theta_{b}^{2} / a_{F}\right)\left(y_{0} / D\right) \sqrt{y_{0}}$ or

$t_{B 0} \sim\left(\Delta \Theta_{b}^{2} / a_{F}\right)\left(y_{0}^{3 / 2} / D\right)$

Despite the semi-empirical approach, the forms of (13), (14) and (15) incorporate several physical facts: (i) The increase of the fuel layer thickness $y_{0}$ increases the preboilover time [5-9]. (ii) The increase of $\Delta \Theta_{b}$ leads to increase of $t_{B 0}$, i.e., higher fuel boiling points and lower fuel initial temperatures delay the boilover onsets. Moreover, lower thermal diffusivity of the fuel $a_{F}$, longer pre-boilover period. (iii) The increase of the pan diameter (see Eq. (15)) reduces the pre-boilover time $t_{B 0}$, since higher pan size, higher burning rate and increased heat reflux to the fuel surface (see the comments of Hamins et al. [22] and the experiments of Garo et al. [6,9]).

\subsection{DAM equations}

\subsubsection{Source term normalization}

The normalization of the volumetric source term yields the number $N_{\mathrm{VA}}$ :

$$
\begin{aligned}
N_{\mathrm{VA}} & =\left[\frac{\mu \dot{q}_{s}^{\prime \prime} t_{0}}{\rho_{F} C_{p}\left(T_{s}-T_{\infty}\right)}\right]=\left(\frac{\mu}{y_{0}} a_{F} t_{0}\right)\left[\frac{\dot{q}_{s}^{\prime \prime} y_{0}}{\lambda_{F}\left(T_{S}-T_{\infty}\right)}\right] \\
& =\frac{\text { heat generated inside the layer }}{\text { heat flux through the fuel layer }}
\end{aligned}
$$

The assumption that $t_{0}=y_{0}^{2} / a_{F}$ is the time scale yields $N_{\mathrm{VA}}=\left(\mu y_{0}\right) N_{0}$, where

$N_{0}=\left[\frac{\dot{q}_{s}^{\prime \prime} y_{0}}{\lambda_{F}\left(T_{s}-T_{\infty}\right)}\right]$

The new dimensional transfer number $N_{0}$ has no a specific name in fire studies (see Thomas [24]). It is known also as a radiation-to-conduction parameter (see Appendix A). The expression of $N_{0}$ (Eq. (17)) incorporates the specificity of the pool fires that the heat reflux to the fluid surface is controlled by radiation-dominated mechanism [14]. The use of $t_{0}=y_{0}^{2} / a_{F}$ leads in a more informative dimensionless form of Eq. (8)

$\frac{\partial \Theta}{\partial t^{*}}=\frac{\partial^{2} \Theta}{\partial y^{* 2}}+N_{0}\left(\mu y_{0}\right) \exp \left[-\left(\mu y_{0}\right) y^{*}\right]$
The number $N_{0}$ expressed through the pool fire parameters (see the scaling Eq. (2)) is:

$$
\begin{aligned}
& N_{0}=\Omega_{0} \frac{1}{\sqrt{y_{0} / D}} y_{0}^{1.5}, \\
& \Omega_{0}=\frac{4}{\pi} \chi \frac{\rho_{\infty} C_{p}\left[T_{\infty} g\left(T_{f}-T_{\infty}\right)\right]^{1 / 2}}{\lambda_{F}\left(T_{s}-T_{\infty}\right)}
\end{aligned}
$$

The value of $\Omega_{0}$ can be assumed as a constant since the flame temperature is approximately constant about $1100 \mathrm{~K}$ for hydrocarbon pool fires (see, for example, Ref. [15] as well as [25-27]), while $\mu\left(\mathrm{m}^{-1}\right)$ and $\chi$ are specific characteristics of the fuel [21,22]. At the $t=t_{B 0}$ the variable $\Theta$ becomes a constant $\Theta_{b 0}=\left(T_{\mathrm{bw}}-T_{\infty}\right) /\left(T_{S}-T_{\infty}\right)$ and the pre-boilover time follows via the Fourier number.

$$
\begin{aligned}
F^{e} & =\Phi^{-1}\left[\Theta_{B 0}\right]^{p}\left(\mu y_{0}\right)^{n}\left(N_{0}\right)^{m} \\
& \approx\left(\Theta_{B 0}\right)^{p}\left(\Omega \frac{1}{\sqrt{y_{0}} / D}\right)^{m}\left(\mu y_{0}\right)^{n}
\end{aligned}
$$

where $p, m$ and $n$ and the function $\Phi$ (and $\Phi^{-1}$, respectively) could be determined by a data fitting procedure.

\subsubsection{Preliminary estimates of the order of magnitude of the source term of Eq. (18)}

The dimensionless groups developed allow an analysis of the sources term of DAM equation. The attenuation factor $\left(\mu y_{0}\right) \exp \left\lfloor-\left(\mu y_{0}\right) y^{*}\right\rfloor$ may be evaluates as follows [18]: (i) the Bouguer number $\left(\mu y_{0}\right)$ calculated for some fuels (data of $[6,7,17,22,28-30]$ are treated) varies approximately from 0.5 to 5 ; (ii) the term $\exp \left\lfloor-\left(\mu y_{0}\right) y^{*}\right\rfloor \rightarrow 1$ at the fuel surface (see Table 5). Therefore, $\left(\mu y_{0}\right) \exp \left\lfloor-\left(\mu y_{0}\right) y^{*}\right\rfloor \equiv \mathrm{O}(1)$, so the main effect comes from the magnitude of $N_{0}$.

Eq. (19) gives that $N_{0}=\Omega_{0} y_{0} \sqrt{D}$. The analysis of the order of magnitude of $\Omega_{0}$ based on the data of Garo et al. [5-7,9,10], and Koseki [8,20] indicates that $\Omega_{0} \equiv$ $\mathrm{O}\left(10^{2}\right)$. For such small laboratory fires $(D<1 \mathrm{~m})$, and $y_{0} \leqslant 10 \mathrm{~mm}$ ) [6,9] the order of magnitude of $N_{0}$ is about $N_{0} \equiv \mathrm{O}\left(10^{2}\right) \mathrm{O}\left(10^{-3}\right) \mathrm{O}(\sqrt{D}) \equiv \mathrm{O}\left(10^{-2}\right)$, while for relatively thicker beds, but with $D<1 \mathrm{~m}$ [20], we should have $N_{0} \equiv \mathrm{O}\left(10^{2}\right) \mathrm{O}\left(10^{-2}\right) \mathrm{O}\left(10^{-1}\right) \equiv \mathrm{O}\left(10^{-1}\right)$.

Therefore, in the case of small-scale laboratory vessels and thin fuel layers the source term could be accepted as negligible with respect of the other terms of the equation having $\mathrm{O}(1)$ that transforms DAM model into SAM one.

The experiments of Blinov and Khudyakov [2], Arai et al. [21] and Imamura et al. [25] exhibit violent fuel ejections from the pan. In these cases $\mathrm{O}(\sqrt{D}) \equiv \mathrm{O}\left(10^{-1}\right)$ and $\mathrm{O}\left(y_{0}\right) \equiv \mathrm{O}\left(10^{-3}\right)$ yield $N_{0} \equiv \mathrm{O}\left(10^{-2}\right)$, that immediately leads to SAM equations. On the other hand, for relatively thicker fuel beds $[8,20]\left(y_{0} \approx(15-30 \mathrm{~mm}) \equiv \mathrm{O}\left(10^{-2}\right)\right)$ and $\mathrm{O}(\sqrt{D}) \equiv \mathrm{O}(1)$ we have $N_{0} \equiv \mathrm{O}(1)$ like the other terms of DAM equation.

The large pool diameters within the range of $1-10 \mathrm{~m}$ (the experiments of Chatris at al. [31] and more that $100 \mathrm{~m}$, like in the case of oil spills) are usually related to thin fuel layers that yield $y_{0} \equiv \mathrm{O}\left(10^{-2}\right)$. This leads to a source term of (18) 
Table 5

Fractions of the heat reflux and the absorption coefficients of some fuels discussed here

\begin{tabular}{|c|c|c|c|c|c|c|}
\hline \multirow[t]{2}{*}{ Fuel } & \multicolumn{2}{|c|}{ Heat reflux data } & \multicolumn{2}{|c|}{ Heat absorption data } & \multicolumn{2}{|c|}{$B u=\mu y_{0}{ }^{b}$} \\
\hline & $\chi \times 10^{3}$ & $\begin{array}{c}\text { Ref. } \\
\text { source }\end{array}$ & $\begin{array}{c}\mu \\
{\left[\mathrm{m}^{-1}\right]}\end{array}$ & $\begin{array}{c}\text { Ref. } \\
\text { source }\end{array}$ & $\min$ & $\max$ \\
\hline Heating oil & & & 262 & [7] & $\begin{array}{c}0.524 \\
y_{0}=2 \mathrm{~mm}\end{array}$ & $\begin{array}{c}4.978 \\
y_{0}=19 \mathrm{~mm}\end{array}$ \\
\hline $\begin{array}{l}\text { Weathered oil } \\
\text { ( } 20 \% \text { water) }\end{array}$ & 1.8 & {$[6]$} & - & - & - & - \\
\hline Crude oil & - & - & 369 & [7] & - & - \\
\hline Alberta sweet oil & - & - & $445^{\mathrm{b}}$ & {$[28]$} & $\begin{array}{c}0.89 \\
y_{0}=2 \mathrm{~mm}\end{array}$ & $\begin{array}{c}6.675 \\
y_{0} \sim 15 \mathrm{~mm}\end{array}$ \\
\hline Toluene & 13 & {$[22]$} & 140 & Garo et al. $[6,9]$ & $\begin{array}{c}1.82^{\mathrm{b}} \\
y_{0}=13 \mathrm{~mm}\end{array}$ & \\
\hline Toluene & - & - & $145^{\mathrm{b}}$ & [28] & $\begin{array}{c}0.29 \\
y_{0}=2 \mathrm{~mm}\end{array}$ & $\begin{aligned} & 2.175 \\
y_{0} & \sim 15 \mathrm{~mm}\end{aligned}$ \\
\hline$n$-Decane & & & 160 & [7] & $\begin{array}{c}1.88 \\
y_{0}=13 \mathrm{~mm}\end{array}$ & \\
\hline Hexane & & & 412 & [29] & & \\
\hline
\end{tabular}

a At $298 \mathrm{~K}$;

b Calculated here.

of order of $\mathrm{O}(1)$. Therefore, it could suggest that DAM is adequate for thicker laboratory beds and large fuel spills.

The real thank fires need a special concern, since they are real fire-fighter "nightmares". Their large dimensions $(D=20-100 \mathrm{~m})$, as well as the fact that the ratio $y_{0} / D \equiv$ $\mathrm{O}(1)$ result in $\Omega \equiv \mathrm{O}\left(10^{2}\right), y_{0} \equiv \mathrm{O}(10)$ and $\sqrt{D} \equiv \mathrm{O}(10)$. Thus, the resulting source term becomes of order magnitude of $\mathrm{O}\left(10^{4}\right)$. However, the estimations are tentative and no experimental confirmations exist.

The above analysis allows to estimate a relationship between the type of the boilover and the order of magnitude of $N_{0}$. The violent fuel ejections [2,21] correspond to $N_{0} \equiv \mathrm{O}\left(10^{-2}-10^{-1}\right)$. The increase of the pan diameter "shifts" the value of $N_{0}$ towards $N_{0} \equiv \mathrm{O}(1)$ and the smoother boilover behaviour. These estimations follow from the existing published data. They should be accepted upon the restrictions of the present analysis, which does not concern either the water layer heating or the heat transfer through the walls. The exact values of $N_{\mathrm{VA}}$ (calculated through Eq. (19)) are summarized in Table 2.

\section{Critical comments on the results developed}

The fact that $F_{O}<1$ at $t=t_{B 0}$ may be interpreted as [18]: as

$$
\begin{aligned}
F_{O}{ }^{e} & =\frac{a_{F}}{y_{0}^{2} / t_{B 0}}=\frac{\text { thermal diffusivity of the fuel layer }}{\text { diffusivity of the hot zone }} \leqslant 1 \\
& \Longrightarrow t_{B 0}<t_{0}
\end{aligned}
$$

The term "diffusivity of the hot zone" [18] is a qualitative interpretation. It tries to explain the heat transfer mechanisms in the burning layer like the term "velocity of the thermal wave" $U_{T}=y_{0} / t_{B 0}$ (see Tables 2 and 4) employed in the previous studies $[6,8,9,20]$.
The use of $y_{0}$ in $F_{o}{ }^{e}$ should overestimate $t_{B 0}$, since the layer diminishes continuously. In this consequence, the use of the mean values of the regression rate $R_{\mathrm{AV}}$ allows to calculate the fuel layer unburned at $t=t_{B 0}$ expressed as $\left(\Delta / y_{0}\right)$, where $\Delta=R_{\mathrm{AV}} t_{B 0}$. The data in Table 2 clearly indicate that at $t=t_{B 0}$ almost $50-60 \%$ of the initial fuel layer is burnt. Therefore, the definition of the velocity $U_{T}=$ $y_{0} / t_{B 0}$ employed in all previous studies on boilover and the hot wave diffusivity are idealizations not strictly relevant to the problem.

The very thin fuel layers $(<3-5 \mathrm{~mm}$ ) [6,9] (see Table 2) allow to apply the fixed boundary approach due to a small fraction of the liquid burnt at $t<t_{B 0}$. These cases, with relatively low regression rates $[6,9]$ are relevant to the SAM equations with $\mathrm{O}\left(N_{0}\right) \ll 1$.

Both groups of models lead to practically similar results. However, the DAM formulation is more adequate, since Eq. (19) incorporates a term $\left(\sqrt{y_{0} / D}\right)^{-1}$ following automatically via normalization of the equations, while in the case of SAM (Eqs. (14), (15)) it was introduced through semi-empirical scaling. However, both models have an important deficiency, since they do not consider the transport phenomena at the burning interface. This deficiency becomes stronger when $N_{\mathrm{VA}} \ll 1$. Moreover, the neglecting of the heat flux coming from the flame to the surface by the use of Dirichlet condition indicates that we neglect the physical phenomena at the flaming interface. Therefore, the main question is, does the boundary condition at the fuels surface employed by both types of models is adequate? The next step is to formulate adequate dimensionless group through a correct formulation of the boundary condition at the flameliquid interface. 


\section{More adequate condition at the burning surface}

\subsection{Normalization of the energy balance at $y=y(t)$}

Starting intuitively, because of the knowledge of physical phenomena controlling the process, the more adequate boundary condition considered here is the energy balance (Eq. (3)) at the interface. Concerning Eq. (4) and the dimensionless variables defined, the energy balance at the burning surface (3) (Stefan boundary condition- $\mathbf{S B C}$ ) is

$\underbrace{\frac{q_{S}^{\prime \prime} y_{0}}{\lambda_{F}\left(T_{s}-T_{\infty}\right)}}_{B_{\mathrm{SA}}}=\underbrace{\left[\frac{H_{V}}{C_{P}\left(T_{S}-T_{\infty}\right)}\right]}_{S t e^{-1}} x \underbrace{\left[\frac{y_{0} r(t)}{a_{F}}\right]}_{N_{\mathrm{DHS}}}-\frac{\partial \Theta}{\partial y^{*}}$

or

$B_{\mathrm{SA}}=\frac{N_{\mathrm{DHS}}}{\text { Ste }}-\frac{\partial \Theta}{\partial y^{*}} \Longrightarrow 1=\frac{N_{\mathrm{DHS}}}{B_{\mathrm{SA}} S t e}-\frac{1}{B_{\mathrm{SA}}} \frac{\partial \Theta}{\partial y^{*}}$

The left side of (22) is $B_{\mathrm{SA}}=\frac{q_{s}^{\prime \prime} y_{0}}{\lambda_{F}\left(T_{s}-T_{\infty}\right)}$ analogous to the Biot number (see Appendix A). The right-hand side of (22) contains two groups

Ste $=\frac{\text { Latent heat }}{\text { Sensible heat }}$ and

$N_{\text {DHS }}=\frac{\text { Diffusivity of moving Heat Source }}{\text { Thermal diffusivity }}$

The former is the Stefan number [32,33], while the group $N_{\text {DHS }}$ has no specific name and can be defined as Diffusivity of the Heat Source. In the specific situation here, Moving Heat Source is the burning fuel surface (more precisely, Line Heat Source [33] for the present 1-D problem formulation). The group $N_{\mathrm{DHS}}$ resembles the Peclet number, Pe $=(u l / a)$ in the case of a convection and a moving heat source (Ref. [33, p. 387]) and needs a knowledge of the mean regression rate that is specific for the fuel $[34,35]$. Thus, the more adequate formulation of (20) is:

$F o=\Phi\left\{\Theta_{B 0}, B u, N_{0}\right.$, Ste,$\left.N_{\mathrm{DHS}}\right\}$

The variations of $F^{e}$ and the two new groups Ste and $N_{\text {DHS }}$ are summarized in Tables 2 and 4 for some fuels investigated by different research groups.

\section{Scaling to published experimental data}

\subsection{Correlations with negligible heat absorption effects}

The first step before the regression analysis is to define which groups will be involved. The solution depends on the orders of magnitudes. For laboratory pans and thin fuel layers $[6,9]$, we have $B_{\mathrm{SA}}=N_{0} \equiv \mathrm{O}\left(10^{-2}\right)$, so both groups should drop from the equations. Therefore, upon such conditions the temperature profile across the fuel is $\Theta=f\left(F o, N_{\text {DHS }}\right.$, Ste $)$.

The preliminary scaling of data (data of Garo et al. [6, 9] (those included in Table 2 and more not presented here)

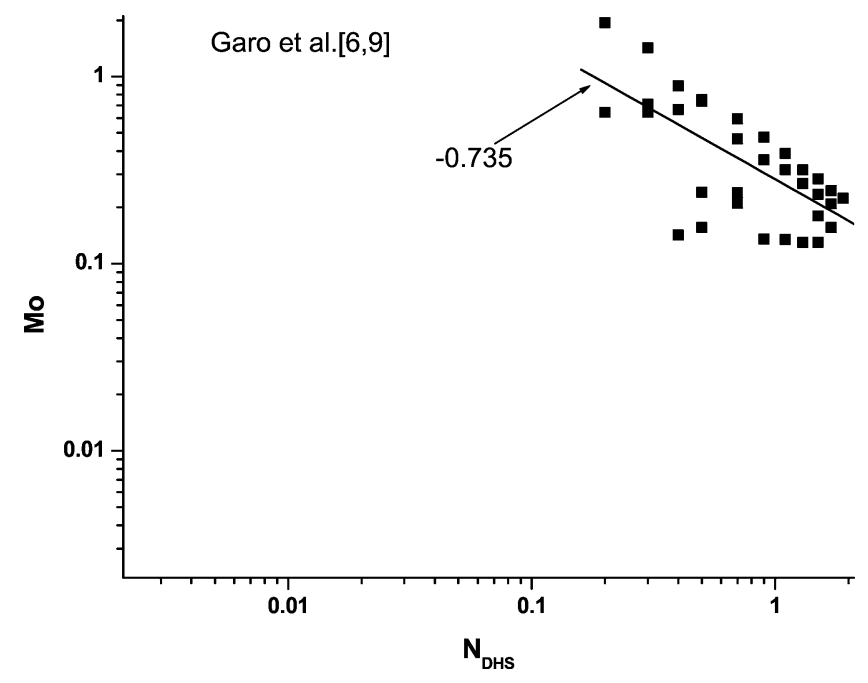

(a)

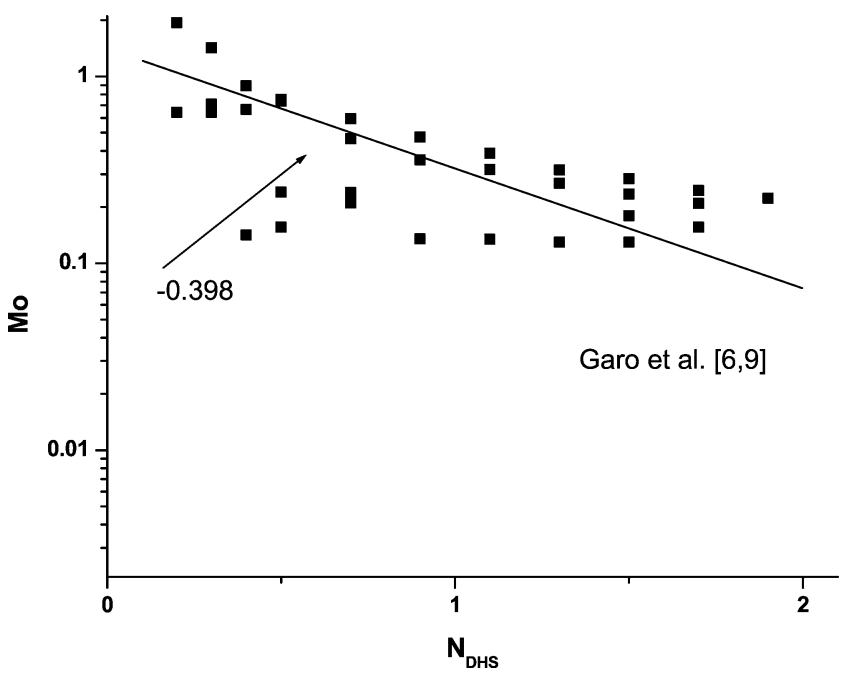

(b)

Fig. 2. Scaling estimates of $M o \sim N_{\text {DHS }}$ for data of Garo et al. [5-7, $9,10]$ in two potential estimates upon the restrictions imposed by the SAM equations and the Stefan boundary condition: (a) Log-Log scaling procedure; (b) Semi-log scaling.

yields $F O \sim(S t e)^{-2}$ (see also data of [21] summarized in Table 3). The contribution of the term $\left(\Theta_{B 0}\right)$ was assumed as $\left(\Theta_{B 0}\right)^{Z} \equiv\left(\Theta_{B 0}\right)^{2}$ based on the experimental data scaling (see Eqs. (14), (15)). Therefore, the desired functional form is

$F O \sim\left(N_{\text {DHS }}\right)^{n}\left(\frac{\Theta_{B 0}}{\text { Ste }}\right)$

The data of Garo et al. [6,9] (Table 2) (0.95 confidential interval) yield (Fig. 2(a)):

$M_{0}=\left[F o\left(\frac{\text { Ste }}{\Theta_{B 0}}\right)^{2}\right] \sim\left(N_{\mathrm{DHS}}\right)^{-0.735}$

On the other, hand the semi-logarithmic $\left(\log _{10}\right)$ presentation (Fig. 2(b)) gives a linear relationship

$\log M_{0}=0.88-0.398 N_{\text {DHS }}$ 
For the experiments of Garo et al. [6,9], the calculated temperature ratio is about $\Theta_{\mathrm{bw}}=0.335$ (initial fuel conditions at $\approx 20^{\circ} \mathrm{C}$ and $T_{\mathrm{bw}}=373 \mathrm{~K}$ ), while $N_{\text {DHS }}$ varies within the range $0.2<N_{\mathrm{DHS}}<1.9$. The fit covers data over the range $5 \times 10^{6}<N_{\mathrm{VA}}<10^{-2}$. Please bear in mind that the preliminary estimation performed in 4.2 .2 is $\mathrm{O}\left(N_{\mathrm{VA}}\right) \equiv$ $\mathrm{O}\left(10^{-2}\right)$.

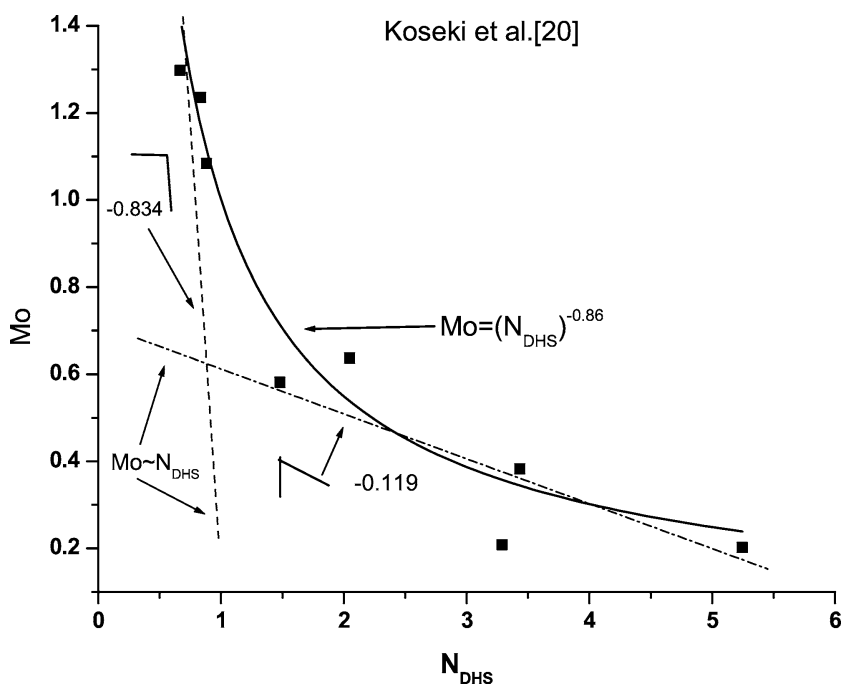

Fig. 3. Scaling estimates $M o \sim N_{\text {DHS }}$ for the data of Koseki et al. [20] in the case of SAM equation and Stefan boundary condition.

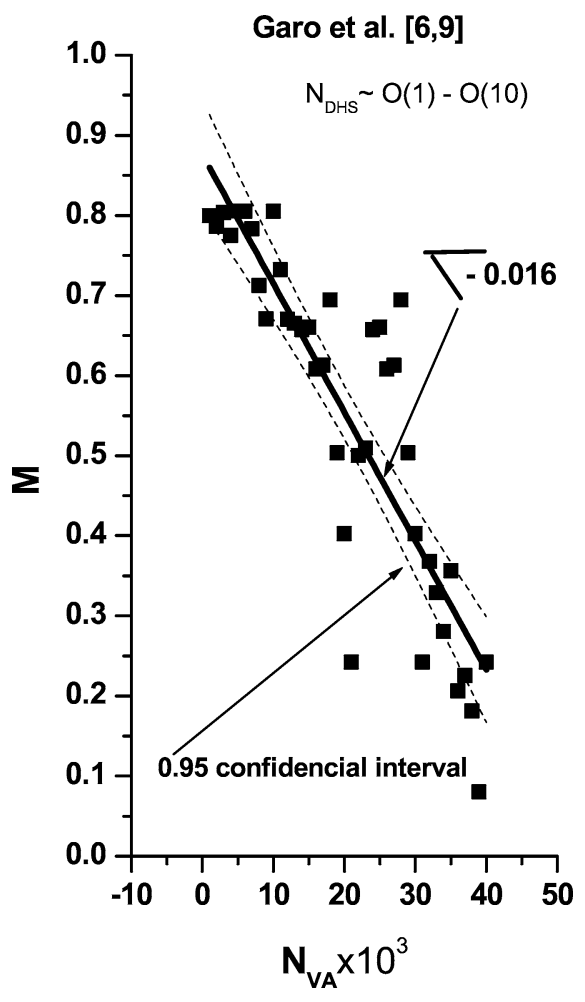

(a)
The data of Koseki et al. [20] (at $\Theta_{\mathrm{bw}}=0.432$-at ambient initial fuel temperature) confirm the linear relationship Fo $\sim 1 /\left(N_{\text {DHS }}\right)^{n} \simeq\left(N_{\text {DHS }}\right)^{-0.86}$ (the solid line in Fig. 3) obtained with the data of Garo et al. [6,9]. Moreover, they allow two linear approximations with negative slopes (dotted lines in Fig. 3) corresponding to different order of magnitudes of $N_{\mathrm{DHS}}$. The latter fact indicates a more complex data behavior, since $B_{\mathrm{SA}} \equiv \mathrm{O}(1)$ and $N_{\mathrm{DHS}} \equiv \mathrm{O}(1)-\mathrm{O}(10)$ (see the comments below).

The scaling of experimental data, just commented, in the case of neglected generation number demonstrates the importance of the processes at the burning surface and especially of the pseudo Peclet number $N_{\mathrm{DHS}}$.

\subsection{Correlations with the $N_{\mathrm{VA}}$ group}

Neglecting the heat absorption effects through $N_{\mathrm{VA}}$ and $B_{\mathrm{SA}}$ groups, we obtained satisfactory data correlations only for the data of Garo et al. [6,9]. On the other hand, Garo et al. [6,9] did not ignore the source term of the equation that yielded satisfactory numerical simulations in dimensional forms. Therefore, a question could be formulated. Is it possible to ignore the preliminary analysis and to include the source term into the correlations? Following the best rules of the dimensional analysis performed by inspection, if you have three-term equation (DAM, for example) the nondimensialization provides two dimensionless groups- $F O$

Koseki et al.[20]

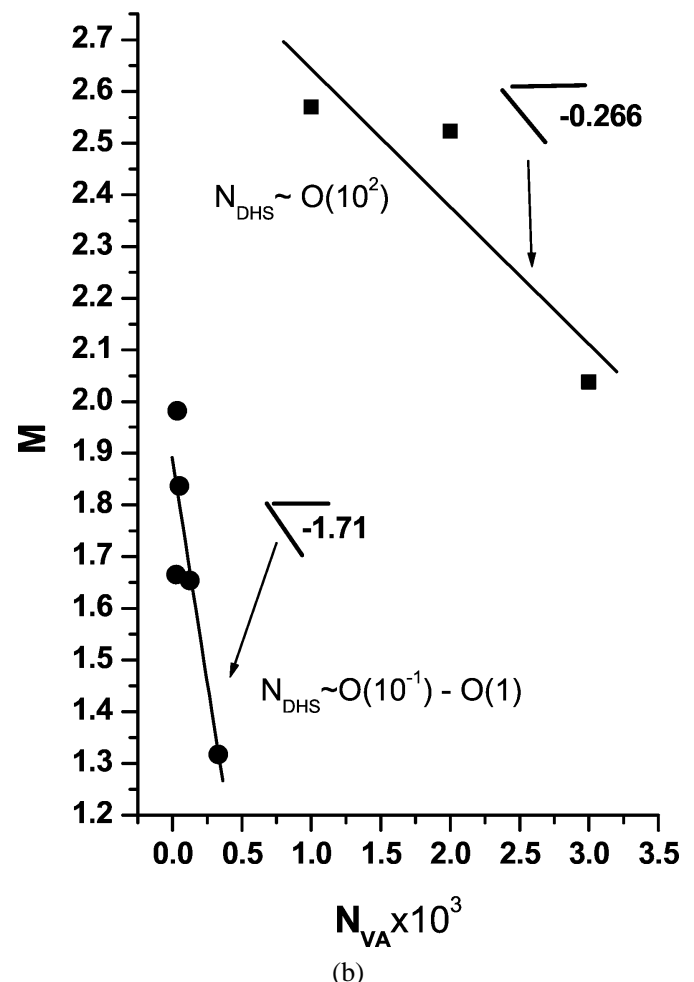

Fig. 4. Data fitting through the generation number $N_{\mathrm{VA}}$ over a large range of variations of $N_{\text {DHS }}$ : (a) Data of Garo et al. [5-7,9,10]; (b) Data of Koseki et al. [20]. The above correlation was performed upon average flame temperature of about $1100 \mathrm{~K}$, attenuation coefficients summarized in Table 5 and the fraction of heat release was accepted as $\chi=2.4 \times 10^{-3}$ (following Garo et al. [6,9], see Table 5 too). 
and $N_{\mathrm{VA}}$. The groups derived from the boundary condition will only affect the coefficients of the power-law relationship $F o=f\left(N_{\mathrm{VA}}\right)$ Simple experiments yield (see Fig. 4(a))

$M=\left[F o N_{\mathrm{DHS}}\left(\frac{\text { Ste }}{\Theta_{B 0}}\right)^{2}\right]=1.01-0.016 N_{\mathrm{VA}}^{\prime}$

where $N_{\mathrm{VA}}^{\prime}=N_{\mathrm{VA}} \times 10^{3}$. The correlation spans a range of variations of $N_{\mathrm{DHS}}$ larger than that corresponding to previous scaling estimates.

The data of Koseki et al. [20] (Fig. 4(b)) confirm the linear relationship $M \sim N_{\mathrm{VA}}$ obtained with the data of Garo et al. [6,9] on Fig. 4(a). Moreover, they demonstrate the effect of the $N_{\text {DHS }}$ number on the functional relationship $M=f\left(N_{\mathrm{VA}}\right)$. The upper group of points on Fig. 4(b) corresponds to the ticker fuel beds burnt in a $1 \mathrm{~m}$ diameter pan (see Table 2), while the points at lower left corner of the graph represents the thinner fuel layers. Both groups of points correspond to the linear approximations in Fig. 3 (the dashed lines). The insufficient data points allow estimations of scaling exponents only, but not of reliable correlations. The correlation with $N_{\mathrm{VA}}$ practically yields the same result like in the absence of source term analyzed in the previous point. The "trick" is that $N_{\mathrm{VA}}$ from the governing equation and $B_{\mathrm{SA}}$ from the boundary condition are interrelated$N_{\mathrm{VA}}=\left(\mu y_{0}\right) B_{\mathrm{SA}}=B u \cdot B_{\mathrm{SA}}$ (see Appendix A).

\subsection{More comprehensive presentation through the dimensionless groups}

The above analysis allows to evaluate the particular contribution of each group on the variation of the boilover Fourier number $\mathrm{Fo}^{e}$. However, these groups exhibit concurrent effects and the influences of those representing the heat absorption effects are more complex. Following the best rules of the dimensionless analysis, combinations of pi- groups could minimize the number of dimensionless variables. The main idea follows from Eq. (24), so we have

$H p=\frac{B_{\mathrm{SA}} \text { Ste }}{N_{\mathrm{DHS}}}=\frac{g_{s}^{\prime \prime}}{\rho_{f} r(t) H_{V}}=\frac{\dot{q}_{s}^{\prime \prime}}{\dot{m}^{\prime \prime} H_{V}}$

In other words, the pseudo Biot number (Eq. (22b)) is $B_{\mathrm{SA}}=H p N_{\mathrm{DHS}} \frac{1}{\mathrm{Ste}}$.

The new group $H p$ and the fact that $N_{\mathrm{VA}}=B u B_{\mathrm{SA}}$ permit to express the boilover Fourier number in a more compact form $F o=\Phi^{-1}\left\lfloor\left(\Theta_{B 0}\right)^{p}(H p)^{m} B u^{n}\right\rfloor$. However, the function $\Phi$ is not defined that requires some additional scaling estimates. The scaling of the boilover Fourier number with the group $H p$ was performed in a form (without a contribution of the Bouguer number $\mathrm{Bu}$ )

$M_{1}=\frac{F o}{\left(\Theta_{B 0}\right)^{2}}=f\left(H p^{m}\right)$

In fact, the plot on Fig. 5(a) repeats qualitatively the $M=$ $f\left(N_{\mathrm{VA}}\right)$ graph on Fig. 4(a), since $H p \sim B_{\mathrm{SA}}\left(S t e / N_{\mathrm{DHS}}\right) \sim$ $B_{\mathrm{SA}}\left(\mu y_{0}\right)\left(\right.$ Ste $\left./ N_{\mathrm{DHS}}\right) \sim N_{\mathrm{VA}} \cdot$ Const. Moreover, it repeats also the scaling plots $M_{0} \sim N_{\text {DHS }}$ (see Fig. 2(a), (b)), where the $N_{\mathrm{VA}}$ is omitted from the family of dimensionless groups (SAM equations with Stefan boundary condition). With the latter situation the only dimensionless groups generated by the boundary condition (Eq. (3)) are $N_{\mathrm{DHS}}$ and Ste.

It was found out, that data of Koseki et al. [20] (Fig. 5(b)) fit well to the reciprocal value $1 / H p$, that is a behaviour just opposite to that on Fig. 4(b), but with two well defined areas of the effects of $N_{\text {DHS }}$. The latter should be accepted as a tentative estimate due to insufficient data for reliable correlations.

The new Hp number employs only macroscopic data that are available preliminary (before the experiments or accidents). Moreover, the number $H p$ implicitly incorporates the effect of the pool diameter through the scaling equation (2). However, $H p \ll 1$ (see Fig. 5(a)) because of the higher values of $H_{V} \equiv \mathrm{O}\left(10^{6}\right) \mathrm{J} \cdot \mathrm{kg}^{-1}$, i.e. due to the low values of $B_{\mathrm{SA}} \equiv \mathrm{O}\left(10^{-2}\right)$. Generally, $H p$ group minimizes the number of quantities involved in predicting of the pre-boilover

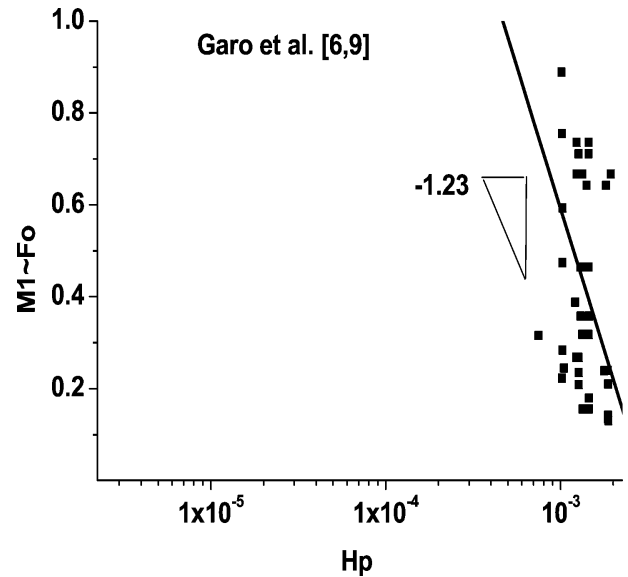

(a)

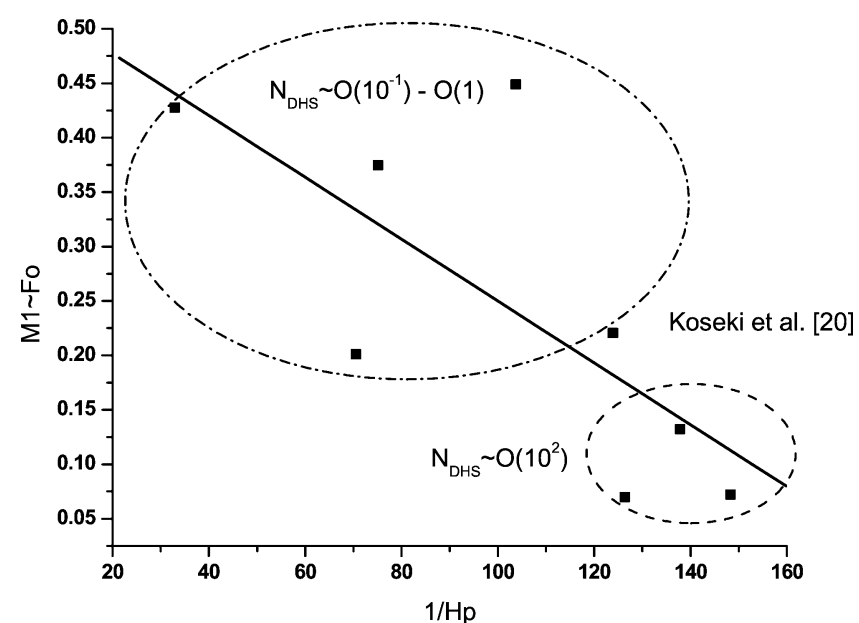

(b)

Fig. 5. Scaling estimates of $F o \sim H p$ : (a) Data of Garo et al. [6,9]; (b) Data of Koseki et al. [20]. 
time and the $\mathrm{Fo} \sim \mathrm{Hp}$ relationship is easy transformable into charts for particular fuels (see Section 7.5).

\subsection{Brief asymptotic analysis employing $N_{\mathrm{VA}}$ and $\mathrm{Hp}$ numbers}

From a fundamental point of view and as well as for the safety engineering purposes two limiting situations are interested: (1) Fo $\rightarrow \infty$, i.e. no boilover occur practically, and (2) $\mathrm{Fo} \rightarrow 0$, that implies an immediate boilover. The plots on Figs. 3 and 4 will be used to develop the analysis.

The case $F o \rightarrow \infty$ means that $N_{\text {DHS }} \rightarrow 0$ (see Eq. (28b) and Figs. 2(a), (b) and 3) (or $1 / H p \rightarrow \infty$ ) that could occur if: $r(t) \rightarrow 0$ (difficult to burn fuel) or $y_{0} \rightarrow 0$ (extremely thin fuel layer), or $a_{F} \rightarrow \infty$ (that is impossible, since $a_{F}$ is a transport property of the medium).

The case $F o \rightarrow 0$ implies $y_{0} \approx 0$ (no fuel layer exist, that is non-sense) or $a_{F} \rightarrow \infty$ which is unrealistic as commented above.

The intermediate situations could be analyzed through the plots on Figs. 3 and 4(a). At $N_{\mathrm{VA}} \rightarrow 0$ (i.e., no absorption effects exist or the fuel does not burn, $y_{0} \approx 0$, or extremely narrow vessel, $D \approx 0$ ), the value of $M \rightarrow 1$ (really $\approx 0.88$ ) (see Fig. 4(a)). This means that,

$$
\begin{aligned}
M \approx 1 & \rightarrow F o \equiv\left(\frac{\Theta_{B 0}}{\text { Ste }}\right)^{2} \frac{N_{\mathrm{VA}}}{N_{\mathrm{DHS}}} \simeq 1 / N_{\mathrm{DHS}} \\
& \rightarrow 1 \Longrightarrow N_{\mathrm{DHS}} \approx 1
\end{aligned}
$$

This confirm the plot on Fig. 3 where the common area of both linear approximation (the convex of the main curve) corresponds to $M o \equiv \mathrm{O}(1)$ and $N_{\mathrm{DHS}} \equiv \mathrm{O}(1)$. Thus, from (25a), we have

$$
M o \equiv \mathrm{O}(1) \rightarrow F o \equiv \underbrace{\left(\frac{\Theta_{\mathrm{bw}}}{S t e}\right)^{2}}_{\mathrm{O}(1)} N_{\mathrm{DHS}} \approx 1
$$

Therefore, at $F o \rightarrow 1$, e.g., $N_{\text {DHS }} \sim \mathrm{O}(1)$, the thermal time scale $t_{0}=\left(y^{2} / a_{F}\right)$ defines the pre-boilover time that corresponds to the assumption of Arai et al. [21] (see Table 1). As $F o \ll 1$, i.e., for large $H p$ numbers (or extremely high values of $N_{\text {DHS }}$ ) the idea expressed by Eq. (21) (the diffusivity of a hot zone) should fail since it means that hot zone propagates faster that the temperature field, that is unrealistic. For example, the condition $F o \ll 1$ (i.e., $t_{B 0} \ll t_{0}$ ) [2,21] allows close form analytical solutions (see Table 1). However, at large values of $H p$ (large pool fires on deep beds) no pure heat conductivity transfer should be considered in the fuel bed.

\subsection{Suggestions about the power law function [36]}

The exponents of the function $F o=\Phi^{-1}\left\lfloor\left(\Theta_{B 0}\right)^{p} \times\right.$ $\left.(H p)^{m} B u^{n}\right\rfloor$ can be defined through a regression analysis of experimental data. The pre-boilover experimental time [1$10,12,18]$ is proportional to the initial fuel thickness $y_{0}$, so we could expect that

$$
\begin{aligned}
t_{B 0} \propto & \Longrightarrow \underbrace{\left(t_{B 0} / t_{0}\right)}_{F o} \propto\left(y_{0} / t_{0}\right) \Longrightarrow F o \propto y_{0} /\left(y_{0}^{2} / a_{F}\right) \\
& \Longrightarrow F o \propto 1 / y_{0} \Longrightarrow F o \sim 1 / B u
\end{aligned}
$$

The data (of Garo et al. [6,9]) scaled to the $H p$ yield Eq. (28) (see Fig. 5(a)). Moreover, $F^{e} \sim 1 / N_{\text {DHS }}$, so taking into account the budget of the $H p$ we could expect a relationship in the form $\mathrm{Fo} \sim \mathrm{Hp}^{m}$. This suggestion permits to develop a dimensionless relationship in the form

$F o \sim\left(\frac{\Theta_{B 0}^{2}}{B u}\right) \cdot H p^{m}$

Physically, the pre-factor $\left(\Theta_{B 0}^{2} / B u\right)$ depends only on the initial fuel thickness through the Bouguer number $\mu y_{0}$, while the main phenomena controlling the process are at the flaming surface and represented by the $H p$ number. The functional relationship (32) should be considered as instructive for fitting experimental data.

\section{Alternative scaling}

The main feature of the above scaling is the use of the initial fuel layer depth $y_{0}$ as a length scale as the only-known dimension of the fuel layer. However, we have a moving boundary problem, so the correct analysis requires both the length and the time scales to be independent of $y_{0}$. The brief examples performed below consider the DAM equation with a Stefan boundary condition (SBC).

Furthermore, we will try to define the true length and time scales of the process depending on the heat transport mechanism assumed.

\subsection{The true scales of the process and asymptotic situations}

However, the question about the true length scale of the process depending on the dominating transport phenomena is open. Let assume that the unknown length scale is denoted by $S_{L}$, while the time scale is $S_{t}$

Assuming

$\Theta=\frac{\left(T-T_{\infty}\right)}{\left(T_{S}-T_{\infty}\right)}, \quad t^{*}=\frac{t}{S_{t}} \quad$ and $\quad y^{*}=\frac{y}{S_{L}}$

after the non-dimensialization we have:

$$
\begin{aligned}
\frac{\rho_{F} C_{p}\left(T_{s}-T_{\infty}\right)}{S_{t}} \frac{\partial \Theta}{\partial t^{*}} \\
=\underbrace{\frac{\lambda_{F}\left(T_{s}-T_{\infty}\right)}{S_{L}^{2}}\left(\frac{\partial^{2} \Theta}{\partial y^{* 2}}\right)}_{\text {Heat conduction }}-\underbrace{\mu q_{s}^{\prime \prime}\left[-\left(\mu S_{L}\right) y^{*}\right]}_{\text {Heat absorption }}
\end{aligned}
$$

Two asymptotic physical situations could be suggested depending on the contributions of heat transfer mechanism suggested as a dominating one (see the terms of Eq. (33)): 
- Heat conduction dominating (HCD) mechanism, that corresponds to SAM equations.

- Heat absorption mechanism (HAD), that implies a dominating role of the source them of the model.

The first suggestion leads to a dimensionless equation

HCD: $\quad\left(\frac{S_{L}^{2}}{a_{F} S_{t}}\right) \frac{\partial \Theta}{\partial t^{*}}$

$$
=1\left(\frac{\partial^{2} \Theta}{\partial y^{* 2}}\right)-\frac{\mu \dot{q}_{s}^{\prime \prime} S_{L}^{2}}{\lambda_{F}\left(T_{s}-T_{\infty}\right)} E x_{0}
$$

while the second one yields

HAD: $\quad \frac{\rho_{F} C_{p}\left(T_{s}-T_{\infty}\right)}{\mu q_{s}^{\prime \prime} E x_{0}}\left(\frac{1}{S_{t}}\right) \frac{\partial \Theta}{\partial t^{*}}$

$$
=\frac{\lambda_{F}\left(T_{s}-T_{\infty}\right)}{\mu q_{s}^{\prime \prime} E x_{0}}\left(\frac{\partial^{2} \Theta}{\partial y^{* 2}}\right)-1
$$

where $E x_{0}=\exp \left\lfloor-\mu S_{L} y^{*}\right\rfloor$. The term $E x_{0} \leqslant 1$, where 1 corresponds to the burning surface.

\section{Head conduction mechanism}

Setting all the coefficients of the dimensionless equations (34a) equal to 1 we have:

$S_{L}=L_{0}=\frac{\lambda_{F}\left(T_{s}-T_{\infty}\right)}{q_{s}^{\prime \prime}} \quad$ and $\quad S_{t}=\tau_{2}=\frac{S_{L}^{2}}{a_{F}}$

The scales $L_{0}$ and $\tau_{2}$ are the so-called alternative "ablation" scale employed in the ablation problems [37]. The comment concerns the physical analogy with ablation process [38] as a moving boundary process as well as with a phase transition at the moving surface. These scales allow to express simply the Stefan boundary condition as

$1=\frac{1}{H p}-\frac{\partial \Theta}{\partial y^{*}}$

The "boilover" Fourier number defined via the new scales is $\widetilde{F} o^{e}=a_{F} t_{B 0} / L_{0}^{2}$. It is easy related to the old $F_{o}^{e}$ through $\widetilde{F} o_{2}^{e}=a_{F} t_{B 0} / L_{0}^{2}=F_{O}^{e}\left(y_{0} / L_{0}\right)^{2}$. Moreover, the source term defines new generation number expressed $\widetilde{N}_{\mathrm{VA}}=\widetilde{B} u N_{0}\left(L_{0} / y_{0}\right)$. Taking into account the definition of $L_{0}$ we have that $\widetilde{B} u=B u\left(L_{0} / y_{0}\right), N_{0}=y_{0} / L_{0}$ and $\widetilde{N}_{\mathrm{VA}}=B u\left(L_{0} / y_{0}\right)$.

\section{Heat absorption mechanism}

The dimensionless coefficients of source tem of (34b) defines $S_{L}=Z_{0}=\lambda_{F}\left(T_{s}-T_{\infty}\right) / q^{\prime \prime}$ Similarly, the dimensionless coefficient of the unsteady term defines $S_{t}=\tau_{3}=$ $1 / \mu^{2} a_{F}$ like in the radiation-to-conduction problems (see Liu and Tan [38], for example). Thus, the length equals that of HCD, but the absorption coefficient $\mu$ determines the time scale. The latter yields a boilover Fourier number $F_{0}^{e}=\left(\mu^{2} a_{F}\right) t_{B 0}$ or through the old Fourier number as $F_{0}^{e}\left(\mu^{2} a_{F}\right) t_{B 0}=F_{o}^{e}\left(y_{0}\right)\left(\mu y_{0}\right)^{2}=F_{o}^{e} B u^{2}$. The source term (the generation number) resembles that defined for the HCD mechanism: $B^{\prime} u=B u\left(Z_{0} / y_{0}\right)$ and $N_{\mathrm{VA}}^{\prime}=B u\left(Z_{0} / y_{0}\right)$.
Table 6

Comparison of the time scales. Summarized results from Section 8.2.2. The cross-box of the columns and the rows correspond to the equality of the time scales

\begin{tabular}{llll}
\hline & $t_{0}$ & \multicolumn{1}{c}{$\tau_{2}$} & \multicolumn{1}{c}{$\tau_{3}$} \\
\hline$t_{0}$ & - & When & When \\
& - & $y_{0}=\frac{\lambda_{F}\left(T_{s}-T_{\infty}\right)}{q_{s}^{\prime \prime}} ; N_{0}=1$ & $y_{0}=\frac{\lambda_{F}\left(T_{s}-T_{\infty}\right)}{q_{s}^{\prime \prime}}$ \\
& & and $\tilde{N}_{\mathrm{VA}}=B u$ & and $N_{0} \cdot B u=1$ \\
& & When \\
$\tau_{2}$ & - & $L_{0}=\frac{\lambda_{F}\left(T_{s}-T_{\infty}\right)}{q_{s}} ;$ \\
& & & and $N_{0}=B u$ \\
\hline
\end{tabular}

Therefore, the determination of the length scales by both suggested heat transfer mechanisms confirms the length scale $L_{0}$ (or $Z_{0}$ ). This length transforms in a unique manner the SBC in a form expressed by Eq. (36) and defines the Hp number. However, formally the time scales of both mechanisms are different. It is easy to demonstrate that the definition of $S_{t}$ given by (35) is transformable as $S_{t}=$ $S_{L}^{2} / a_{F}=\left(1 / \mu^{2} a_{F}\right) B u^{2}\left(S_{L} / y_{0}\right)^{2}$.

Formally, if the length scale of the HCD mechanism is chosen as $S_{L}=1 / \mu$ (this is an alternative following from the mechanistic treatment of the source term) the time scale is $S_{t}=1 / \mu^{2} a_{F}$, but this is not consistent with the heat transfer conduction mechanism considered.

However, the only measurable length is the initial fuel depth $y_{0}$. The question arising is: do some conditions exist upon which $t_{0}=y_{0}^{2} / a_{F}$ is the process time scale. The definition of $y_{0}$ implicitly assumes the HCD mechanism, so the simple check $t_{0}=\tau_{2}$ (see (35)) yields $y_{0}=L_{0}$. The latter condition implies $1 / N_{0}=1$ that yields a generation number $\widetilde{N}_{\mathrm{VA}}=B u$. This condition gives real values of $\widetilde{N}_{\mathrm{VA}}$ in the range of $10^{-1}-10$ (see the values of $B u$ in Table 4). Similarly, we could set $t_{0}=\tau_{3}$ and $\tau_{2}=\tau_{3}$. Table 6 summarizes the results of that comparison.

\subsection{Boundaries of the regimes suggested-tentative estimates}

As a first step, let concern the conduction dominating mechanism, that corresponds to the SAM equation and the primarily defined scales $y_{0}$ and $t_{0}$. The condition $N_{\mathrm{VA}} \ll 1$ applied to the source term (see Eq. (17)) requires:

$N_{\mathrm{VA}} \ll 1 \Longrightarrow B u N_{0} \ll 1, \quad$ or $\quad N_{0} \ll \frac{1}{B u}$

Therefore, (see the values of $B u$ in Table 5), we should have $N_{0} \equiv \mathrm{O}\left(10^{-1}-1\right)$ or less.

The opposite heat transfer mechanism concerns a domination of the source term, so for the dimensionless coefficient of the heat diffusion term should satisfy the condition (see Eq. (34b))

$\frac{\lambda_{F}\left(T_{s}-T_{\infty}\right)}{q_{s}^{\prime \prime}} \frac{\mu}{E x_{0}}=\frac{B u}{N_{0}} \frac{1}{E x_{0}} \ll 1$ 
Taking into account that $1 / E x_{0}>1$, a more weak, but a sufficient, form of the condition (39) could be expressed as $B u / N_{0} \ll 1$, or $N_{0} \gg B u$. The latter requires values of $N_{0}>5-7$, so at least we should have $N_{0} \equiv \mathrm{O}\left(10-10^{2}\right)$.

Let us take a backward glance over the data commented in Section 4.2.1 where the order of magnitude of $N_{0}$ was established based on the fuel layer dimensions only. The order of magnitude $N_{0} \equiv \mathrm{O}\left(10^{-1}-1\right)$ or less is typical for small laboratory fires, for explosive boilover behaviour, and for the Conduction Dominated heat transfer mechanism determined by $S A M$ equations. On the other, hand $N_{0} \equiv$ $\mathrm{O}(1)-\mathrm{O}\left(10^{2}\right)$ corresponds to smoother boilover, Absorption Dominated heat transfer and consequently to the DAM equation.

\subsection{Asymptotic situations}

This attempt stresses the attention on the areas where the derived dimensionless group could control the process. The conduction-dominated mechanism described by the SAM equation has a simple solution (see Table 1) represented in a classical manner through dimensionless groups available in every textbook on heat transfer, so it will not be commented here.

A very interesting situation providing new results (see further) occurs if we suggest the domination of the heat absorption only. Omitting the heat diffusion term of the DAM equation (see (34b)) and employing the intrinsic length and time scales $\tau_{3}$ and $L_{0}$ we have

$\frac{\partial \Theta}{\partial t^{*}}=-\frac{1}{\mu L_{0}} \exp \left(-\mu L_{0} y^{*}\right)$

That gives

$\Theta=C_{0} t^{*}+C_{1}$

where $C_{0}=\frac{1}{\mu L_{0}} \exp \left(-\mu L_{0} y^{*}\right)$ and $C_{1}=0$, since $\Theta=0$ at $t^{*}=0$, and $y^{*}=y_{s}(t) / L_{0}$.

The expression of (40) through dimensionless groups (taking into account that $t^{*}=\mathrm{FO}_{3}$ ) becomes

$\Theta=\left(\frac{N_{0}}{B u}\right)^{2}\left[\mathrm{Fo}_{3}^{2}-\frac{N_{\mathrm{DHS}}}{N_{0}} \mathrm{Fo}_{3}\right]$

The expression (41) allows a simplification since $N_{\text {DHS }} / N_{0} \ll 1$ (the values of $N_{\text {DHS }}$ are available in Table 2 ), so we have

$\Theta \approx\left(\frac{N_{0}}{B u}\right)^{2}\left[F_{3}^{2}\right] \Longrightarrow \mathrm{Fo}_{3} \approx \sqrt{\Theta} \frac{B u}{N_{0}}$

\section{Explicit scaling and similarity tests}

The power-law function was commented several times through the text. Moreover, some suggestions about its form were done in Section 7.5 as a result of the preliminary analysis with the scales $y_{0}$ and $t_{0}$. The following analysis, try to derive scaling relationships for the pre-boilover time in explicit forms in the three cases discusses above as well as similarity rules.

\subsection{Explicit (dimensional) scaling estimates}

Case A. Scales $y_{0}$ and $t_{0}$ (no dominating heat transfer mechanism is assumed and ad hoc defined scales): The suggestion that $F_{1}^{e} \propto 1 / B u$ and $F_{o}^{e} \propto H p$ done earlier (see Section 7.5), and $B u \propto y_{0}$ as well as that $H p \propto q_{s}^{\prime \prime} \propto \sqrt{D}$ (the scaling Eq. (2)) yield an explicit scaling

$F_{o}^{e} \propto \frac{t_{B 0}}{y_{0}^{2}} \equiv \frac{1}{B u} H p \Longrightarrow t_{B 0} \propto y_{0} \sqrt{D} \quad$ or

$t_{B 0} \propto\left(\frac{y_{0}}{D}\right) \frac{1}{\sqrt{D}}$

Case B. Scales $L_{0}$ and $\tau_{2}$ (conduction dominated heat transfer).

Similarly, with $F_{2}^{e} \propto 1 / L_{0}^{2}$, and $\left.\widetilde{B} u \propto L_{0}\right)$ it follows that $t_{B 0} \sim L_{0} \sqrt{D}$. Further, considering that $N_{0}=y_{0} / L_{0}=$ $B_{\mathrm{SA}} \propto H p$ (see the expression (36)) we have

$t_{B 0} \propto \frac{y_{0}}{N_{0}} \sqrt{D}=\frac{y_{0}}{\sqrt{D}} \sqrt{D}=\left(\frac{y_{0}}{D}\right) D$

that is very close to the form expressed by Eq. (15).

Case C. Scales $L_{0}$ and $\tau_{3}$ (absorption dominated heat transfer).

The scaling follows from the simplified solution (43) and the relationships $\mathrm{Fo}_{3}^{e}=\mathrm{Fo}^{e} \mathrm{Bu}^{2}$, so

$$
\begin{gathered}
F_{3}^{e}=\left(\mu a_{F}\right) t_{B 0}=F o_{1}^{e} B u^{2} \approx \sqrt{\Theta} \frac{B u}{N_{0}} \\
\Longrightarrow F o_{1}^{e} \approx \frac{1}{B u} \frac{1}{N o} \propto \frac{1}{B u} \frac{1}{H p} \\
t_{B 0} \propto y_{0} \frac{1}{H p} \propto y_{0} \frac{1}{\sqrt{D}}=\left(\frac{y_{0}}{D}\right) \sqrt{D}
\end{gathered}
$$

The above explicit scaling estimates are expressed especially through the common group $\left(y_{0} / D\right)$ in order to do a parallel with the experimentally derived relationships (14) and (15). Generally, the explicit scaling estimates can be interpreted as

$$
\begin{aligned}
t_{B 0} \sim & \text { (initial fuel conditions) } \\
& \quad(\text { conditions at the flaming interface }) \sim y_{0} D^{n}
\end{aligned}
$$

where the scaling exponent $n$ depends on the heat transfer mechanism across the fuel layer.

\subsection{Direct tests of the explicit scaling estimates}

The common expressions of the dimensional scalings in the forms (42)-(45) do permit scaling in $\log t_{D}-\log D$ co-ordinates, where $t_{D}=t_{B 0} / y_{00}$ and $y_{00}=y_{0} / D$. The variations of the scaling exponent $n$ for experiments with pool diameters varying from $0.15 \mathrm{~m}$ up to $4 \mathrm{~m}$ and conditions spanning both the "thick" and the "thin" layer boilovers are shown on Fig. 6. 


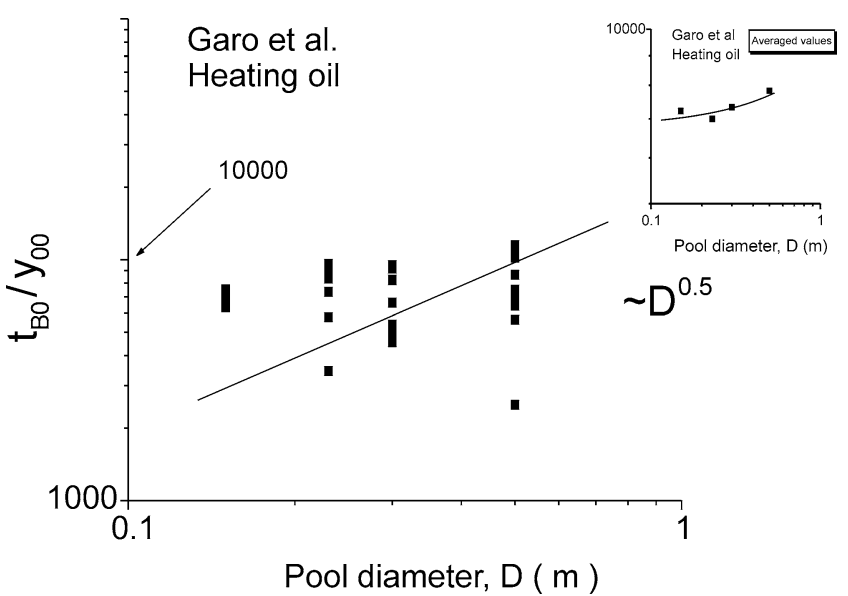

(a)

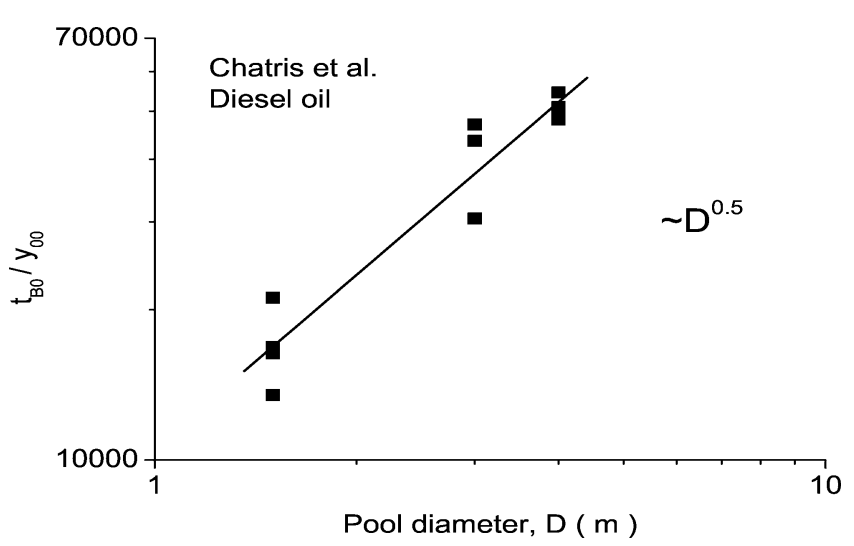

(c)

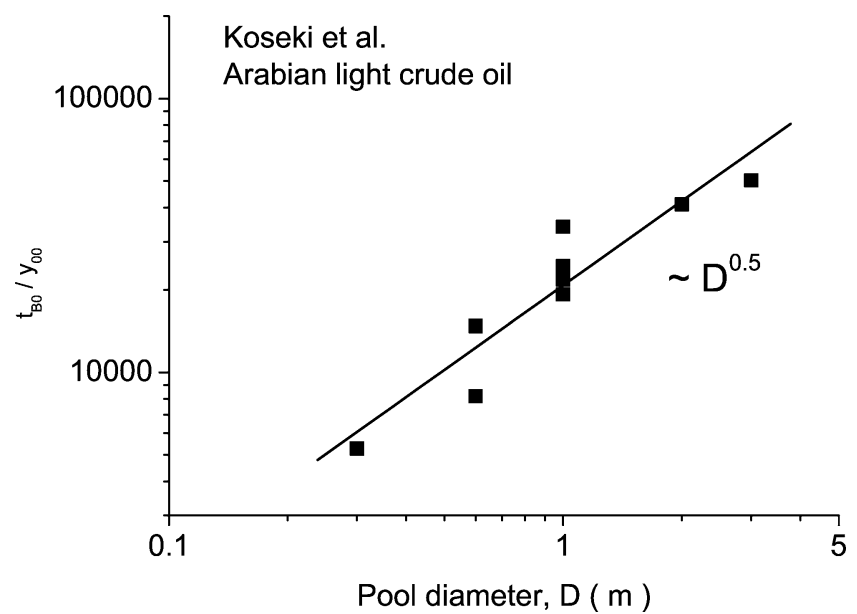

(b)

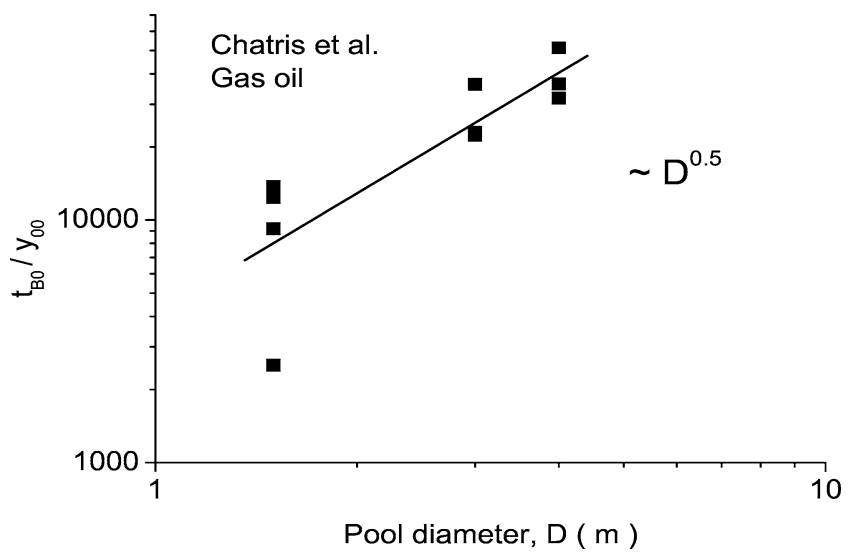

(d)

Fig. 6. Evaluation of the scaling exponent $n$ and a test of the theory predictions for four experimental situations: (a) Laboratory experiments of Garo et al. [6,9]-All the data summarized in Table 2 and those from experiments with pool of $0.5 \mathrm{~m}$ (not shown here, but available in [18]). (b) Laboratory and semi-field scale experiments of Koseki et al. [20]—data summarized in Table 2. (c) Field experiments of Chatris et al. [31]—gasoline. (d) Field experiments of Chatris et al. [31] - diesel oil. Note: The experiments of Chatris et al. are described in the original paper, but some data relevant to the present study are summarized in Table 7.

Table 7

Conditions of the experiments of Chatris et al. [37]. Additional information to Fig. 6

\begin{tabular}{|c|c|c|c|c|c|c|c|}
\hline \multirow[t]{8}{*}{ Diesel oil } & $D=1.5 \mathrm{~m}$ & $y_{0}, \mathrm{~mm} \rightarrow$ & 6.6 & 6.6 & 7.4 & 7.9 & 8.9 \\
\hline & & $t_{B 0}, \mathrm{~s} \rightarrow$ & 83 & 93 & 83 & 87 & 80 \\
\hline & & $y_{0}, \mathrm{~mm} \rightarrow$ & 6.6 & 7.3 & 8.0 & & \\
\hline & $D=3.0 \mathrm{~m}$ & & & & & & \\
\hline & & $t_{B 0}, \mathrm{~s} \rightarrow$ & 67 & 106 & 125 & & \\
\hline & & $y_{0}, \mathrm{~mm} \rightarrow$ & 7.8 & 8.9 & 9.5 & 9.6 & \\
\hline & $D=4.0 \mathrm{~m}$ & & & & & & \\
\hline & & $t_{B 0}, \mathrm{~s} \rightarrow$ & 116 & 107 & 121 & 117 & \\
\hline \multirow[t]{9}{*}{ Gas oil } & & $y_{0}, \mathrm{~mm} \rightarrow$ & 7.4 & 8.0 & 11.3 & & \\
\hline & $D=1.5 \mathrm{~m}$ & & & & & & \\
\hline & & $t_{B 0}, \mathrm{~s} \rightarrow$ & 61 & 49 & 19 & & \\
\hline & & $y_{0}, \mathrm{~mm} \rightarrow$ & 8.0 & 8.1 & 9.0 & & \\
\hline & $D=3.0 \mathrm{~m}$ & & & & & & \\
\hline & & $t_{B 0}, \mathrm{~s} \rightarrow$ & 61 & 98 & 67 & & \\
\hline & & $y_{0}, \mathrm{~mm} \rightarrow$ & 6.7 & 7.3 & 9.0 & & \\
\hline & $D=4.0 \mathrm{~m}$ & & & & & & \\
\hline & & $t_{B 0}, \mathrm{~s} \rightarrow$ & 86 & 58 & 82 & & \\
\hline
\end{tabular}

The help of Origin performed the plots (at 0.95 confidential intervals) yield $t_{D} \sim \sqrt{D}$ more or less. The data of Garo et al. $[6,9]$ demonstrate $t_{D} \sim D^{0.2}-D^{0.4}$ due to the large scattering of the data points. The attempt to scale the averaged (arithmetic mean) values of $t_{D}$ for each pool diameter studied by Garo et al. [6,9] yields $t_{D} \sim D^{0.4}$ (see the inset of Fig. 6(a)). Thus, it could suggest that the heat conduction across the fuel dominates for smaller diameter pool fires and the scaling corresponds to the case B, while for $D=0.3-$ $5 \mathrm{~m}$ pools the heat absorption starts to dominate and the scaling approaches the case $\mathrm{C}$. The increase of pool diameter shifts the heat transfer controlling mechanism and all the data scale of Koseki et al. [8] and those of Chatris et al. [31] scale $t_{D} \sim \sqrt{D}$, thus confirming the prediction done for the Case C (see Eq. (47b)).

The results are reasonable, since from $t_{D} \sim \sqrt{D}$ it follows $t_{B 0} \sim 1 / \sqrt{D}$. However, we should keep in mind that the data contain implicit information about the transition between both heat transfer mechanisms suggested. For example, the lower range of the pool diameters employed 
by Koseki et al. [8] spans the upper range of the pool sizes of the experiments of Garo et al. [6,9] (see Table 2). It could assume that the general tendency of the data of Koseki et al. (the scaling to $D^{0.5}$ ) is due to the larger pool diameters employed. In the same time, the lower range of the pool size range investigated by Chatris et al. [31] overlaps the upper range of pools in the experiments of Koseki et al. [8]. The former can be clearly defined as a thin-layer boilover. The fact that the pre-boilover time scales to $D^{0.5}$ is a possible explanation of the scattering of the experimental data reported by Koseki [40] (Fig. 8 of the referred paper) and correlated only to the initial fuel thickness $y_{0}$.

\subsection{Similarity between pool fire experiments}

Following the general form of the power-law function in two systems (two pool fires) of different sizes the equality of the Fourier numbers $F o(1)$ and $F o(2)$ implies

$$
\frac{1}{B u(1)} H p(1)^{m}=\frac{1}{B u(2)} H p(2)^{m}
$$

Following the expression for case C (Eq. (47b)) and assuming that the mass burning rate does not depend on the pool diameter (a strong simplification about the contribution of $H p$ number) we have

$$
\begin{gathered}
\frac{1}{\mu_{1} y_{0}(1)} \frac{1}{\sqrt{D_{1}}}=\frac{1}{\mu_{2} y_{0}(2)} \frac{1}{\sqrt{D_{2}}} \\
\Longrightarrow \frac{y_{0}(1)}{y_{0}(2)}=\frac{\mu_{2}}{\mu_{1}} \frac{\sqrt{D_{2}}}{\sqrt{D_{1}}}
\end{gathered}
$$

The expression gives a tentative proportionality, since $a$ pre-factor of the mass combustion rates $m_{1,2}=\dot{m}^{\prime \prime}(1) / \dot{m}^{\prime \prime}(2)$ should exists. This very simple relationship was tested with the data of Garo et al. [6,9] and Koseki et al. [8] summarized in Table 2. In these experiments, the initial fuel thickness was varied gradually, without any attempts to create geometrical similarity at least. The data of Garo et al. [6,9] allow such analysis since the ratio $\dot{m}^{\prime \prime}(1) / \dot{m}^{\prime \prime}(2)$ is almost 1 for all the experiments because the fuel type does not vary, i.e., $\mu_{2} / \mu_{1}=1$. The results summarized in Table 8 indicate that:

(i) No similar experiments have performed systematically;

(ii) Among the data of Garo et al. [6,9] there are several experiments where the requirement (47) is almost satisfied, i.e., those yield close values of $\mathrm{Fo}^{e}$; and

(iii) The data of Koseki et al. [8] are not sufficient to establish any similarity.

This attempt to find similar situations and to draw a rule how to simulate the boilover upon model conditions, and to transfer the data to a prototype, should be concerned as a first step in that direction requiring further development.

\section{Brief conclusions}

The discussion is brief because it was done practically at the length of paper. Generally, we will comments the results en bloc. The paper reached two goals:

(1) To consolidate the data published in various sources, but without any transport phenomena analysis.

(2) To develop a general form of the functional equation defining the pre-boilover time, easy transformable into engineering charts.

Generally, the scale analysis detected the principle dimensionless groups controlling the process. The arbitrary choice of the scales $y_{0}$ and $t_{0}$ demonstrates how many dimensionless groups can be generated if the scales are not intrinsic to the process. Therefore, this first part of the scale analysis demonstrated the more adequate position of the Stefan boundary condition at the burning interface instead the Dirichlet condition employed by the original models (see Appendix B).

The detection of the intrinsic scales clearly demonstrates that the dimensionless number $\mathrm{Hp}$ controls the process. Very important information derived from that analysis is the ability to test the primary physical hypothesis that the contribution of the radiation to the heat transfer across the fuel layer increases with the increase of the pool diameter. Moreover, this simple scaling allowed a similitude test of published data and drew the idea for more systematic experiments.

Blinov and Khudyakov have commented the occurrence of strong convection inside the tanks during fire in their pioneering study [2]. More recent comments and analysis of similar observations are collected in the review of Koseki [39]. Obviously, this should be incorporated in the future models.

The criterion for the boilover onset needs a justification. Physically, but mainly by intuition, all the studies referred in the present paper, assume that water layer explodes when the thermal waves reach the fuel-water interface. It was demonstrated (see in Table 2) that the velocity $U_{T}$ of such thermal wave is physically non-adequate to the process studied. The investigations of Blinov and Khudyakov [2] in very narrow glass cylinders (no data only explanations exist in the original text) indicated that the water temperature could reach values above $100^{\circ} \mathrm{C}$ before the ejection if a thin fuel layer cover its top surface. This point needs special studies on both laboratory and field scales for correct definition of the physical condition of water explosions. The present study employed the water boiling temperature upon atmospheric conditions, but this was an approximation demonstrating the approach of the investigation only.

Finally, the scale analysis is a physical experiments performed by mathematical tools. The adequacy of the models and their restricted or extended abilities directly affects the result of the scaling. 
Table 8

A test for a similitude between some experiments performed

\begin{tabular}{|c|c|c|c|c|c|c|c|}
\hline \multirow{2}{*}{$\begin{array}{c}\mathrm{S} 1 \\
D_{1} \\
{[\mathrm{~mm}]}\end{array}$} & \multirow{2}{*}{$\begin{array}{c}\mathrm{S} 2 \\
D_{2} \\
{[\mathrm{~mm}]}\end{array}$} & \multirow[b]{2}{*}{$\sqrt{D_{1} / D_{2}}$} & \multicolumn{2}{|c|}{$\begin{array}{l}\text { Fuel layers Satisfying the ratio } \\
\qquad \sqrt{D_{1} / D_{2}}\end{array}$} & \multicolumn{2}{|c|}{$\begin{array}{l}\text { Fourier numbers } \\
\text { (Experimental) }\end{array}$} & \multirow[t]{2}{*}{ Comments } \\
\hline & & & $\mathrm{S} 1: y_{0}[\mathrm{~mm}]$ & $\mathrm{S} 2: y_{0}[\mathrm{~mm}]$ & $S 1$ & $S 2$ & \\
\hline \multicolumn{8}{|c|}{ Garo et al. $[6,9]^{\mathrm{a}}$} \\
\hline 0.15 & 0.23 & 1.238 & $\begin{array}{l}19 \\
4\end{array}$ & $\begin{array}{l}C=15.344 \mathrm{~mm} \\
R=15 \mathrm{~mm} \\
C=3.23 \mathrm{~mm} \\
R=3.0 \mathrm{~mm}\end{array}$ & $\begin{array}{l}0.223 \\
0.88\end{array}$ & $\begin{array}{l}0.23 \\
0.71\end{array}$ & $\begin{array}{l}\text { Almost } \\
\text { Similar } \\
\text { Almost } \\
\text { Similar }\end{array}$ \\
\hline 0.15 & 0.3 & 1.414 & $\begin{array}{l}19 \\
17\end{array}$ & $\begin{array}{l}C=13.43 \mathrm{~mm} \\
R=13.0 \mathrm{~mm} \\
C=12.02 \mathrm{~mm} \\
R=11 \mathrm{~mm} \text { and } 13 \mathrm{~mm}\end{array}$ & $\begin{array}{l}0.223 \\
0.245\end{array}$ & $\begin{array}{l}0.268 \\
0.318 \\
0.268\end{array}$ & $\begin{array}{l}\text { Almost } \\
\text { Similar } \\
\text { Close, but not similar }\end{array}$ \\
\hline & & & 13 & $\begin{array}{l}C=9.19 \mathrm{~mm} \\
R=9 \mathrm{~mm}\end{array}$ & 0.316 & 0.358 & $\begin{array}{l}\text { Almost } \\
\text { Similar }\end{array}$ \\
\hline 0.15 & 0.5 & 1.824 & & $C=1.14 \mathrm{~mm}$ & & & No similar layer exists \\
\hline 0.23 & 0.3 & 1.142 & $\begin{array}{l}17 \\
15 \\
13 \\
5\end{array}$ & $\begin{array}{l}C=14.88 \mathrm{~mm} \\
R=15 \mathrm{~mm} \\
C d=13.134 \mathrm{~mm} \\
R=13 \mathrm{~mm} \\
C=11.38 \mathrm{~mm} \\
R=11 \mathrm{~mm} \\
C=4.38 \mathrm{~mm} \\
R=4 \mathrm{~mm} \text { and } 5 \mathrm{~mm}\end{array}$ & $\begin{array}{l}0.209 \\
0.235 \\
0.268\end{array}$ & $\begin{array}{l}0.180 \\
0.268 \\
0.318 \\
0.667 \\
0.736\end{array}$ & $\begin{array}{l}\text { Almost } \\
\text { Similar } \\
\text { Almost } \\
\text { Similar } \\
\text { Close, but not similar } \\
\text { Almost } \\
\text { Similar }\end{array}$ \\
\hline 0.23 & 0.5 & 1.474 & $\begin{array}{r}13 \\
7\end{array}$ & $\begin{array}{l}C=4.82 \mathrm{~mm} \\
R=9 \mathrm{~mm} \\
C=4.74 \mathrm{~mm} \\
R=5 \mathrm{~mm}\end{array}$ & $\begin{array}{l}0.268 \\
0.464\end{array}$ & $\begin{array}{l}0.210 \\
0.239\end{array}$ & $\begin{array}{l}\text { Close, but not similar } \\
\text { No confirmation }\end{array}$ \\
\hline 0.3 & 0.5 & 1.666 & 15 & $\begin{array}{l}C=9.0 \mathrm{~mm} \\
R=9.0 \mathrm{~mm} \\
\text { Koseki et al. }[8]\end{array}$ & 0.180 & 0.210 & $\begin{array}{l}\text { Almost } \\
\text { Similar }\end{array}$ \\
\hline 0.3 & $\begin{array}{l}0.6 \\
1.0\end{array}$ & $\begin{array}{l}1.414 \\
1.825\end{array}$ & $\begin{array}{l}35 \\
35\end{array}$ & $\begin{array}{l}C=24.75 \mathrm{~mm} \\
R=20 \mathrm{~mm} \\
C=19.18 \mathrm{~mm} \\
R=20 \mathrm{~mm}\end{array}$ & 0.003 & $\begin{array}{l}0.00835 \\
0.0795\end{array}$ & $\begin{array}{l}\text { No confirmation } \\
\text { No confirmation }\end{array}$ \\
\hline 0.3 & $\begin{array}{l}2 \\
3.5\end{array}$ & $\begin{array}{l}2.581 \\
3.415\end{array}$ & & No geomet & y similar & s exist & \\
\hline 0.6 & $\begin{array}{l}1 \\
2\end{array}$ & $\begin{array}{l}1.290 \\
1.825\end{array}$ & & & & & \\
\hline $\begin{array}{l}0.6 \\
1.0\end{array}$ & $\begin{array}{l}3.5 \\
2 \\
3.5\end{array}$ & $\begin{array}{l}2.415 \\
1.414 \\
1.87\end{array}$ & & & & & \\
\hline 2 & 3.5 & 1.322 & & & & & \\
\hline
\end{tabular}

a The data for the $0.3 \mathrm{~mm}$ pool fire are summarized in [18]; $C$-calculated layer thickness; $R$-real layer.

\section{Acknowledgements}

The works was partially supported by a NATO fellowship, Grant 27/D/01/SP (Jan-June, 2002) and by a visiting professorship supported by the Spanish Ministry of Education, Culture and Sports (July-December, 2002) of one of the authors $(\mathrm{JH})$.

\section{Appendix A. Justification about the dimensionless groups derived}

For example, when the surface flux expressed as $q^{\prime \prime}=$ $\sigma \mathcal{I}\left(T_{\mathrm{ss}}^{4}-T^{4}\right)$ and the body source $q^{\prime \prime \prime}$ contribute the heat conduction through a slab (solid or liquid) of thickness $\delta$ and a volume $V$ exposed to a sudden radiation, two 
dimension1ess groups occur [41]:

$N_{1}=\left(\frac{q^{\prime \prime \prime} \sigma}{\sigma \mathcal{I} T^{4}+T_{\mathrm{ss}}^{4}}\right)^{1 / 4}$ and $M o=\frac{\sigma \mathcal{I} T_{0}^{3} \delta}{\delta}$

The group $N_{1}$ is analogous to $N_{\mathrm{VA}}=\left(\mu y_{0}\right) N_{0}$ in its original form (see Eq. (17)). The group Mo is the radiationn number (or conduction-radiationn parameter or Stark number) [42], analogous to the Biot number and to $B_{\mathrm{SA}}$ number (Eq. (22)). The groups $N_{1}$ and Mo represent the general case when the surfaces flux $q^{\prime \prime}$ and volumetric source $q^{\prime \prime \prime}$ are not interrelated. However, in the case of DAM equations $\dot{q}_{r}^{\prime \prime}=$ $\dot{q}_{S}^{\prime \prime} \exp (-\mu y)$ and consequently $N_{0} \equiv B_{\mathrm{SA}} \equiv\left(\frac{1}{\mu y_{0}}\right) N_{\mathrm{VA}}$, so the source them of Eq. (18) is $N_{0}\left(\mu y_{0}\right) \exp \left\lfloor-\left(\mu y_{0}\right) y^{*}\right\rfloor \sim$ $B_{\mathrm{SA}}$. In other words, the discussion about magnitude of the source them of Eq. (18) is, in fact, a discussion about magnitudes of the number $B_{\mathrm{SA}}$ controlling the process through the boundary, like in the convective heat transfer controlled by the Biot number.

\section{Appendix B. Stefan boundary condition}

The Stefan problem $(S P)$ is well known in the literature and the specific model build-up is available in [43-45], for example. For most of the readers familiar with SP, the introduction of the present article is sufficient to understand the adequacy of SBC. However, this comment try to explain what is the reason to use SBC instead the Dirichlet boundary condition (DBC) mainly for the readers familiar with SBC, but not interested in fire science as well as to those of them working on fires but unfamiliar with SP.

In general, DBC implies infinite heat flux at the boundary. The Stefan condition is the more adequate at the flamefuel boundary since it describes the heat transfer across the interface associated ba its motion and a phase transition (liquid evaporation) that is impossible ba DBC. The heat conduction equation (SAM or DAM) is valid for every point of the fuel layer, while Eq. (3) concerning simultaneously the fuel evaporations and the interface motion, exists only at the boundary. In the Stefan condition, for example, a uniform temperature (i.e., DBC) implies the right-hand side equal to zero and hence here is no movement of the interface and no evaporation can occur $[44,45]$.

\section{References}

[1] B. Broekmann, H.-G. Schecker, Heat transfer mechanisms and boilover in burning oil-water-systems, J. Loss Prev. Process Ind. 8 (3) (1995) 137-147.

[2] V. Blinov, G. Khudyakov, Diffusion Burning of Liquid, Academy of Science, Moscow, 1961, pp. 149-155 (in Russian). The book is available as an English translation: Diffusion burning of liquid, T-1490 ASTIA AD 296762, 1961.

[3] W.C. Fan, J.S Hua, G.X. Liao, Experimental study on the premonitory phenomena of boilover in liquid pool fires on water, J. Loss Prev. Process Ind. 8 (4) (1995) 221-227.
[4] N. Wu, G. Kolb, J. Torero, Piloted ignition of slick of oil on a water sublayer: The effect of weathering, in: Twenty five Symp. (Int.) on Comb., The Combustion Institute, Pittsburgh, 1998, pp. 2783-2790.

[5] J. Garo, J. Vantelon, Thin layer boilover of pure or multicomponent fuel, in: V.E. Zarko, V. Weiser, N. Eisenreich, A.A. Vasil'ev (Eds.), Prevention of Hazardous Fires and Explosions. The Transfer to Civil Applications of Military Experiences, in: NATO Sci. Ser. Ser. 1 Disarmament Technol., vol. 26, Kluwer Academic, Dordrecht, 1999, pp. 167-182.

[6] J. Garo, J. Vantelon, S. Gandhi, J. Torero, Determination of the thermal efficiency of pre-boilover burning of a slick of oil on water, Spill Sci. Technol. Bull. 8 (4) (1999) 221-227.

[7] J. Garo, P. Gillard, J. Vantelon, S. Gandhi, C. Fernandez-Pello, Combustion of liquid fuels spilled on water. Prediction of time to start of boilover, Combust. Sci. Technol. 147 (1999) 39-59.

[8] H. Koseki, G. Mulholland, The effect of the diameter on the burning of crude oil fires, Fire Technol. 27 (1) (1991) 54-65.

[9] J. Garo, J. Vantelon, C. Fernandez-Pello, Experimental study of the burning of a liquid fuel spilled on water, in: Twenty five Symp. (Int.) on Combustion, The Combustion Institute, Pittsburgh, 1994, pp. 14811488.

[10] J. Garo, J. Vantelon, C. Fernandez-Pello, Effect of the fuel boiling point on the boilover burning of liquid fuel spilled on water, in: Twenty-sixth Symp. (Int.) on Combustion, The Combustion Institute, Pittsburgh, 1996, pp. 1461-1467.

[11] E. Twardus, T. Brzustowski, The burning of crude oil spilled on water, Arch. Combust. Polish Acad. Sci. 20 (1-2) (1981) 49-60.

[12] T. Brzustowski, E. Twardus, A study of burning of slick of crude oil on water, in: Nineteen Symp. (Int.) on Combustion, The Combustion Institute, Pittsburgh, 1982, pp. 847-854.

[13] M.A. Alramadhan, V.S. Arpaci, A. Sealamet, Radiation affected liquid fuel burning on water, Combust. Sci. Technol. 72 (1982) 233-253.

[14] D.D. Drysdale, An Introduction to Fire Dynamics, Wiley, New York, 1985.

[15] G. Cox, Combustion Fundamentals of Fire, Academic Press, London, 1995.

[16] N. Wu, M. Backer, G. Kolb, J. Torero, Ignition, flame spread and mass burning characteristics of liquid fuels on a waterbed, in: Proc. 20th AMOP Techn. Sem., Alberta, Canada, June 11-13, vol. 2, 1997, pp. 769-793.

[17] K.S. Mudan, P.A. Croce, Fire hazard calculation for large open hydrocarbon fires, in: SFPE Handbook of Fire Protection Engineering, second ed., 1995, pp. 3-197-3-240.

[18] J. Hristov, Burning of slick of oil on water, in: Chr. Boyadjiev, J. Hristov (Eds.), Transport Phenomena in Two-Phase Flow, September 1116, 2001, Burgas, Bulgaria, 2001, pp. 179-198.

[19] B. Gebhard, Heat Conduction and Mass Diffusion, McGraw-Hill, New York, 1993, pp. 37-42.

[20] H. Koseki, M. Kokkala, G.W. Mulholland, Experimental study of boilover in crude oil fires, in: Fire Safety Science, Proc. of 3rd Int. Symp., Elsevier, London, 1991, pp. 865-874.

[21] M. Arai, K. Saito, R.A. Altenkirch, A study of boilover $i$ liquid pool fires supported on water. Part 1: Effects of a water sublayer on pool fires, Combust. Sci. Technol. 71 (1990) 25-40.

[22] A. Hamins, T. Kashiwagi, R. Burch, Characteristic of pool fire burning, in: P.A. Totem, G.E. Reichel (Eds.), Fire Resistance of Industrial Fluids, Proc. ASTM STP1284, Indianapolis, IN, June 1541, 1996 (available at www.nist.bfrl.gov).

[23] D.B. Spalding, Some Fundamentals of Combustion, Butterworth, London, 1955.

[24] P.H. Thomas, Dimensional analysis: A magic art in fire research?, Fire Safety J. 34 (2) (2000) 111-141.

[25] B. McCaffrey, Flame height (Chapter 1-18), in: P.J. DiNenno (Ed.), The SPFE Handbook of Fire Protection Engineering, first ed., NFPA, Quincy, MA, 1988, pp. 1-298-1-305.

[26] E. Planas-Cuchi, J. Casal, Flame temperature distribution in a poolfire, J. Haz. Mat. (1998) 231-241. 
[27] T.T. Lie, Flame temperature-time relations (Chapter 3-5), in: P.J. DiNenno (Ed.), The SPFE Handbook of Fire Protection Engineering, first ed., NFPA, Quincy, MA, 1988, pp. 3-81-3-87.

[28] T. Imamura, K. Saito, K. Tagavi, A study of boilover $i$ liquid pool fires supported on water. Part 2: Effects of in-depth radiation absorption, Combust. Sci. Technol. 86 (1992) 105-119.

[29] D.S. Burgess, A. Strasser, J. Grumer, Diffusive burning of liquid fuels in open trays, Fire Res. Abstracts Rev. 3 (1961) 177-192.

[30] J. Garo, J. Vantelon, J. Souil, C. Brillat, Burning oil spill-effect of the weathering and water content, in: AIAA/ASME Joint Thermophysics and Heat Transfer Conf., vol. 1, ASME, 1998, pp. 179-190.

[31] J.M. Chatris, J. Quintela, J. Folch, E. Planas, J. Casal, Experimental study of burning rate in hydrocarbon pool fires, Combust. Flame 126 (2001) 1373-1383.

[32] J.P. Catchpole, G. Fulford, Dimensionless groups, Ind. Engrg. Chem. 58 (3) (1966) 46-60.

[33] M.N. Ozisik, Heat Conduction, second ed., Wiley, New York, 1993, pp. 385-389.

[34] B.J. MCafrey, Purely buoyant diffusion flames: Some experimental results, Report of National Bureau of Standards, NBSIR 79-1910.

[35] V. Babrauskas, Burning rates (Chapter 2-1), in: P.J. DiNenno (Eds.), The SPFE Handbook of Fire Protection Engineering, first ed., NFPA, Quincy, MA, 1988, pp. 2-1-2-15.

[36] J.Y. Hristov, E. Planas, J. Arnaldos, J. Casal, Prediction of the preboilover time of tank fires (scaling of 1-D heat transfer models), in: A. Macias-Machin, J. Umbria (Eds.), Proc. of 4th EMChIE Congress, vol. 1, Las Palmas, Spain, 12-14 February, 2003, pp. 207-216.
[37] S.K. Wong, A. Walton, Numerical solution of single-phase Stefan problem using a fictitious material, Nummer. Heat Transfer Part B 35 (1999) 211-223.

[38] W.M. Rohsenow, H.Y. Choi, Heat, Mass and Momentum Transfer (Chapter 6), Prentice-Hall, Englewood Cliffs, NJ, pp. 12-124.

[39] L.-H. Liu, H.-P. Tan, Transient radiation and conduction in a twodimensional participating cylinder subjected to a pulse radiation, Internat. J. Therm. Sci. 40 (2001) 877-889.

[40] H. Koseki, Boilover and crude oil fire, J. Appl. Fire Sci. 3 (3) (1993) 243-271.

\section{References to Appendixes}

[41] P.J. Schneider, Conduction (Chapter 4), in: W.M. Rohsenow, J.P. Hartnett, E.N. Ganic (Eds.), Handbook of Heat Transfer Fundamentals, second ed., McGraw-Hill, New York, 1985, pp. 4-43-4-44.

[42] R. Siegel, J.R. Howell, Thermal Radiation Heat Transfer (Chapter 16), third ed., Taylor \& Francis, Washington, DC, 1992, pp. 821-880.

[43] A.C. Fowler, Mathematical Models in Applied Sciences (Chapter 5), Cambridge University Press, Cambridge, 1998, pp. 67-69.

[44] J. Crank, Free and Moving Boundary Problems (Chapter 1), Clarendon Press, Oxford, 1984, pp. 1-29.

[45] A.B. Tayler, The mathematical formulation of Stefan problems, in: J.R. Ockedon, W.R. Hodgkins (Eds.), Moving Boundary Problems in Heat Flow and Diffusion, Clarendon Press, Oxford, 1975, pp. 120137. 